\title{
Tau Cleavage and Dephosphorylation in Cerebellar Granule Neurons Undergoing Apoptosis
}

\author{
Nadia Canu, ${ }^{1}$ Laura Dus, ${ }^{2}$ Christian Barbato, ${ }^{1}$ Maria T. Ciotti, ${ }^{2}$ Claudio Brancolini, ${ }^{3}$ Anna M. Rinaldi, ${ }^{1}$ \\ Michal Novak, ${ }^{4,5}$ Antonino Cattaneo, ${ }^{4}$ Andrew Bradbury, ${ }^{4}$ and Pietro Calissano ${ }^{1,2}$ \\ ${ }^{1}$ Dipartimento di Neuroscienze, Università di Roma Tor Vergata, 00173 Roma, Italy, 2/stituto di Neurobiologia, Consiglio \\ Nazionale delle Ricerche, 00137 Roma, Italy, ${ }^{3}$ Laboratorio Nazionale Consorzio Interuniversitario Biotecnologie, AREA \\ Science Park, 34142 Trieste, Italy, 4International School for Advanced Studies, Neuroscience Program, 34013 Trieste, \\ Italy, and 5/nstitute of Neuroimmunology, Slovak Academy of Science, 84246 Bratislava, Slovak Republic
}

Cerebellar granule cells undergo apoptosis in culture after deprivation of potassium and serum. During this process we found that tau, a neuronal microtubule-associated protein that plays a key role in the maintenance of neuronal architecture, and the pathology of which correlates with intellectual decline in Alzheimer's disease, is cleaved. The final product of this cleavage is a soluble dephosphorylated tau fragment of $17 \mathrm{kDa}$ that is unable to associate with microtubules and accumulates in the perikarya of dying cells. The appearance of this $17 \mathrm{kDa}$ fragment is inhibited by both caspase and calpain inhibitors, suggesting that tau is an in vivo substrate for both of these proteases during apoptosis. Tau cleavage is correlated with disruption of the microtubule network, and experiments with colchicine and taxol show that this is likely to be a cause and not a consequence of tau cleavage.

These data indicate that tau cleavage and change in phosphorylation are important early factors in the failure of the microtubule network that occurs during neuronal apoptosis. Furthermore, this study introduces new insights into the mechanism(s) that generate the truncated forms of tau present in Alzheimer's disease.

Key words: apoptosis; tau; calpain; caspase; cerebellar granule neurons; Alzheimer's disease
Apoptotic cell death is a fundamental biological process critical for the development of the organism and the maintenance of tissue homeostasis (Steller, 1995). Inappropriate apoptosis is involved in neurodegenerative disorders, including Alzheimer's disease (AD) (Su et al., 1994; Smale et al., 1995; Thompson, 1995; De la Monte et al., 1997).

This form of cell death occurs in two stages: commitment and execution (Steller, 1995). The execution stage, manifested by plasma membrane blebbing, retraction of cellular processes (neurite retraction during neuronal apoptosis), chromatin condensation, fragmentation of DNA, and the formation of apoptotic bodies (Kerr et al., 1972; Cohen, 1993), is initiated by the activation of caspases (Steller, 1995) and other proteases, including calpain, cathepsin D, and the 20S proteasome (Guenette and Tenniswood, 1994; Squier et al., 1994; Grimm et al., 1996; Sadoul et al., 1996).

Many different proteins involved in key cellular processes have been reported to be substrate for these proteases (for review, see Cohen, 1997).

The neuronal cytoskeleton is recognized as being integral to the shape and function of neurons. It is not surprising, therefore, that some of the morphological changes associated with neuronal

\footnotetext{
Received April 1, 1998; revised June 8, 1998; accepted June 24, 1998.

This study was supported in part by a research contract with NE.FA.C. Pomezia, Italy, within the National Research Plan Neurobiogical Systems of the Ministero della Università e della Ricerca Scientifica e Tecnologica, and in part by Progetto Finalizzato Biotecnologie of Consiglio Nazionale delle Ricerche. L.D. was a recipient of a research contract from Sigma Tau. We thank Dr. Andrea Levi and Luisa Fasulo for comments on this manuscript. We are grateful to V. Lee for the generous gift of mAb AT8, PHF-1, T49, and 12E8.

Correspondence should be addressed to Dr. Nadia Canu, c/o Istituto di Neurobiologia, Consiglio Nazionale delle Ricerche, Viale Marx 43, 00137 Roma Italy Copyright (C) 1998 Society for Neuroscience $0270-6474 / 98 / 187061-14 \$ 05.00 / 0$
}

apoptosis involve a significant modification of the cytoskeletal network, a process that is likely to contribute to the subsequent degeneration of neurons after they have undergone apoptosis. One critical component of the neuronal cytoskeleton is tau, the neuron-specific, microtubule-associated protein. Tau consists of a collection of six proteins derived by alternative mRNA splicing of a single gene (Goedert et al., 1989; Himmler et al., 1989). In addition, tau also undergoes a complex pattern of posttranslational changes, including physiological phosphorylation and glycosylation (Lovestone and Reynolds, 1997), as well as pathological phosphorylation (Grundke-Iqbal et al., 1986a), glycosylation (Wang et al., 1996), glycation (Ledesma et al., 1994), and truncation (Novak et al., 1993) in AD.

Tau, through its ability to bind and regulate microtubule (MT) structure and dynamics, is involved in many aspects of MT behavior such as neuronal morphogenesis, maintenance of axonal shape, and transport (Goedert et al., 1991; Hirokawa, 1994). The affinity of tau for MT is regulated by (1) the number of MT binding repeats (Goedert and Jakes, 1990), (2) the proline-rich sequence adjacent to the MT binding domain (Gustke et al., 1994), (3) the anchoring to the plasma membrane via the $\mathrm{N}$-terminal domain (Brandt et al., 1995), and (4) the extent and sites of phosphorylation (Biernat et al., 1993).

Here we used cerebellar granule cells deprived of potassium and serum (D’Mello et al., 1993; Galli et al., 1995) as a model system to study the effects of apoptosis on tau and microtubules.

Our results provide the first evidence that depletion of functional tau occurs during apoptosis. This depletion is mainly caused by calpain and caspase-3-dependent proteolytic cleavage of tau and by a relative increase in the 68-69 $\mathrm{kDa}$ paired helical filament (PHF)-1 phosphorylated isoforms of tau known to be 
unable to bind microtubules. We suggest that these posttranslational modifications of tau contribute to the apoptotic breakdown of the neuronal cytoskeleton.

\section{MATERIALS AND METHODS}

Materials. Colchicine and Paclitaxel were from Sigma (St. Louis, MO). The protease inhibitors $N$-acetyl-Leu-Leu-norLeucinal (ALLN or calpain inhibitor I), $N$-acetyl-Leu-Leu-Methioninal (ALLM or calpain inhibitor II), trans-epoxy succinyl-L-leucylamydo-3-methyl-butane ethyl ester (E64d), and leupeptin were purchased from Sigma. The inhibitor of (ICE)-like protease, acetyl-Tyr-Val-Ala-Asp-cho (Ac-YVAD-cho), was from Bachem (Torrance, CA). Benzyloxycarbonyl-Val-Ala-Aspfluoromethylchetone (z-VAD-fmk) and benzyloxycarbonyl-Asp-Glu-ValAsp-fluoromethylchetone (z-DEVD-fmk) were from Calbiochem (La Jolla, CA). Compounds were dissolved in the amount of dimethyl sulfoxide (DMSO) required to establish stock solutions of $1000 \times$. No more than $0.1 \%$ solvent was present in culture medium.

Neuronal cultures. Cultures enriched in granule neurons were obtained from dissociated cerebella of 8-d-old Wistar rats (Charles River Laboratories, Wilmington, MA) as described by Levi et al., (1984). Cells were plated in basal medium Eagle (BME; Life Technologies, Gaithersburg, MD) supplemented with $10 \%$ fetal bovine serum, $25 \mathrm{~mm} \mathrm{KCl}$, and $2 \mathrm{~mm}$ glutamine (Life Technologies) on dishes (Nunc) coated with poly-Llysine. Cells were plated at $2.5 \times 10^{6}$ per $35 \mathrm{~mm}$ dish or $7 \times 10^{6}$ per 60 $\mathrm{mm}$ dish. $1 \beta$-Arabinof uranosylcytosine $(10 \mu \mathrm{M})$ was added to the culture medium $18-22 \mathrm{hr}$ after plating to prevent proliferation of non-neuronal cells.

Treatment of cultures. Cultures [6-7 d in vitro (DIV)] were washed two times and maintained in serum-free $\mathrm{BME}(5 \mathrm{mM} \mathrm{KCl})$ supplemented with glutamine and gentamicin. Control cells were washed and maintained in serum-free medium containing $25 \mathrm{~mm} \mathrm{KCl}$. Protease inhibitors were added to the cultures once $(2 \mathrm{hr})$ before and once after induction of apoptosis.

Neuronal survival. Neuronal survival was usually assessed by counting the number of intact nuclei, after lysing the cells in detergent-containing solution by the method of Soto and Sonnenschein (1985) modified by Volonté et al. (1994).

Isolation of tau from cerebellar granule cells. Total proteins were extracted by scraping the cells in SDS-reducing sample buffer and then by boiling for $5 \mathrm{~min}$. To obtain tau proteins that are either bound to MTs or free in the cytosol, the cells were scraped from the culture dish into microtubule stabilization buffer $\left(0.1 \mathrm{M}\right.$ MES, $0.5 \mathrm{~mm} \mathrm{MgSO}_{4}, 1 \mathrm{~mm}$ EGTA, 2 mm dithiothreitol, pH 6.8, $0.75 \mathrm{~m} \mathrm{NaCl}, 2 \mathrm{~mm}$ GTP, $20 \mu \mathrm{M}$ taxol) plus $0.1 \%$ Triton $\mathrm{X}-100(\mathrm{v} / \mathrm{v})$ and a mixture of protease and phosphatase inhibitors ( $2 \mathrm{~mm}$ phenylmethylsulfonyl fluoride, $20 \mathrm{~mm} \mathrm{NaF}$, $0.5 \mathrm{~mm}$ sodium orthovanadate, and $N$-tosyl-L-phenylalanine chloromethyl ketone, $N \alpha$ - $p$-tosyl-L-lysine chloromethyl ketone, leupeptin, pepstatin, and soy bean trypsin inhibitor, each at $1 \mu \mathrm{g} / \mathrm{ml}$, homogenized in a glass-Teflon homogenizer (20 strokes). The bound microtubules were sedimented by centrifugation at $13,000 \mathrm{rpm}$ for $15 \mathrm{~min}$ at room temperature and then resuspended in SDS-reducing sample buffer. The resulting supernatant, containing the soluble fraction of the cytoskeleton, was alcohol-precipitated at $-20^{\circ} \mathrm{C}$ and centrifuged, and the resultant pellet was resuspended in MT stabilization buffer (for determination of protein content) and then in $2 \times$ SDS-reducing sample buffer and heated for 5 $\min$ at $95^{\circ} \mathrm{C}$.

Western blot analysis. Equal amounts of protein [determined by the method of Lowry et al. (1951)] from different experimental conditions were subjected to SDS-PAGE on 7-15\% linear gradient gels (Laemmli, 1970). After they were electroblotted to nitrocellulose (Hybond-C), proteins were visualized using appropriate primary antibodies. All primary antibodies were diluted in $0.5 \%(\mathrm{w} / \mathrm{v})$ nonfat dry milk and incubated with the nitrocellulose blot overnight at $4^{\circ} \mathrm{C}$. Incubation with secondary peroxidase-coupled anti-mouse or anti-rabbit antibodies was performed at room temperature for $45 \mathrm{~min}$. Blots were developed by using the ECL system (Amersham, Arlington Heights, IL). Development of Western blots was terminated before band intensity was saturated; relative optical densities and areas of bands were quantified using a computerized image analysis system.

Antibodies. Several anti-tau antibodies were used in this study. They include Tau-1 (Grundke-Iqbal et al., 1986b) (Boehringer Mannheim, Mannheim, Germany), 304 (Goedert et al., 1992), PHF-1 (Greenberg et al., 1992), 12E8 (Seubert et al., 1995), T49 and AT8 (Mercken et al., 1992), MN7.51 (Novak et al., 1991), $\beta$-actin (Sigma), and anti $\alpha$-tyrosinylated tubulin (YL1/2) (Kilmartin et al., 1982). PHF-1, AT8, 12E8, and T49 were kindly provided by Dr. V. Lee (Department of Pathology and Laboratory Medicine, University of Pennsylvania School of Medicine, Philadelphia, PA).

Immunofluorescence. Cerebellar granule cells were fixed with $4 \%(\mathrm{w} / \mathrm{v}$ in PBS) paraformaldehyde for $15 \mathrm{~min}$ at room temperature. Fixed cells were washed in PBS, $\mathrm{pH} 7.5$, and then permeabilized with $0.1 \%$ Triton $\mathrm{X}-100-$ Tris-Cl, $\mathrm{pH} 7.5$, for $5 \mathrm{~min}$. The coverslips were treated with monoclonal antibody (mAb) MN7.51 (1:10) or Tau-1 (1:100) for $1 \mathrm{hr}$ in a moist chamber at room temperature, rinsed in PBS, and stained with FITC-conjugated secondary antibodies (Sigma) for $30 \mathrm{~min}$. Nuclei were stained with Hoechst 33258 (Sigma) $0.5 \mathrm{mg} / \mathrm{ml}$ in PBS for $5 \mathrm{~min}$.

In vitro cleavage reaction by millimolar-calpain. Purified bovine tau (Sigma) or cytoplasmatic extract from cerebellar granule cells at 8 DIV were used for the in vitro tau cleavage assay. After two washes in PBS, cells were lysed in a buffer containing $20 \mathrm{~mm}$ Tris- $\mathrm{HCl}, \mathrm{pH} 7.4,150 \mathrm{~mm}$ $\mathrm{NaCl}, 1 \mathrm{~mm}$ dithiothreitol, $5 \mathrm{~mm}$ EDTA, $5 \mathrm{~mm}$ EGTA, and $1 \%(\mathrm{w} / \mathrm{v})$ Triton $\mathrm{X}-100$ for $1 \mathrm{hr}$ at $0^{\circ} \mathrm{C}$. The lysates were cleared by centrif ugation and stored at $-70^{\circ} \mathrm{C}$ in $50 \%(\mathrm{v} / \mathrm{v})$ glycerol. The cleavage reaction was performed for $10 \mathrm{~min}$ at $30^{\circ} \mathrm{C}$. The reaction mixture $(30 \mu \mathrm{l})$ containing 20 $\mu \mathrm{g}$ of cellular extract was incubated in the presence or absence of purified m-calpain (rabbit skeletal muscle, Sigma), in $50 \mathrm{~mm}$ Tris- $\mathrm{HCl}$, $\mathrm{pH}$ 7.5, $100 \mathrm{~mm} \mathrm{NaCl}, 2 \mathrm{~mm}$ dithiothreitol, $1 \mathrm{~mm}$ EDTA, and $5 \mathrm{~mm}$ $\mathrm{CaCl}_{2}$. The concentration of calpain used in the in vitro cleavage was 0.5 $\mathrm{U} / 20 \mu \mathrm{g}$ tau. The digestion was neutralized by the addition of SDScontaining sample buffer for PAGE and boiling. Samples were subjected to electrophoresis and electrotransfer. The blots were then probed with mAb Tau-1.

In vitro translation and cleavage of tau with caspase-3. Recombinant human caspase-3 with a C-terminal His6 tag was expressed in Escherichia coli as described previously (Brancolini et al., 1997). The recombinant protease was purified on a Ni2+ affinity resin. For the in vitro protease assay Tau [tau40pSG5 (Novak et al., 1993)] was labeled with ${ }^{35} \mathrm{~S}$ using the Transcription N Translation-coupled reticulocyte lysate system (Promega, Madison, WI). Two microliters of translated reticulocyte lysate were incubated with purified caspase-3 in $10 \mu \mathrm{l}$ of caspase-3 buffer (Brancolini et al., 1997) with protease inhibitors (1 mM PMSF and 10 $\mu \mathrm{g} / \mathrm{ml}$ each aprotinin, leupeptin, and pepstatin) for $30 \mathrm{~min}$. at $37^{\circ} \mathrm{C}$. Reactions were terminated by adding 1 vol of SDS gel loading buffer and boiling for $3 \mathrm{~min}$.

\section{RESULTS}

Rat cerebellar granule cells can be induced to undergo apoptosis if the potassium concentration is reduced to $5 \mathrm{~mm}(\mathrm{~K} 5)$ and serum is removed $(\mathrm{S}-)$ after a period of initial growth in $25-30 \mathrm{~mm}$ potassium (K25) and serum (S+) (Gallo et al., 1980; D’Mello et al., 1993; Galli et al., 1995). The apoptosis that is induced decreases the viability of cerebellar granule cells by $>50 \%$ when measured after $24 \mathrm{hr}$ (see Fig. 2A).

\section{Tau is cleaved during neuronal apoptosis}

One of the characteristic changes seen during neuronal apoptosis is an alteration of the cytoskeleton, manifested as an early beading, thinning, and degeneration of neurites followed by blebbing and fragmentation of the cell bodies. This observation led us to investigate the effect of apoptosis on tau, one of the major microtubule-associated proteins (MAPs), which promotes tubulin polymerization and stabilizes microtubules (Drechsel et al., 1992).

Examination of the state of tau in a total extract of cells undergoing apoptosis with the mAb Tau-1, which recognizes a dephosphorylated epitope at 189-207 (Fig. 1) (Szendrei et al., 1993), reveals the appearance of a $17 \mathrm{kDa}$ band (and a ladder of intermediate bands probably corresponding to incomplete cleavage) within $6 \mathrm{hr}$ of inducing apoptosis (Fig. $2 A$ ). Because at this time ( $<6 \mathrm{hr}$ ) apoptosis is largely reversible (Galli et al., 1995) and all cells are still alive and morphologically well preserved (D'Mello et al., 1993), tau cleavage is a very early event in this apoptotic process, a characteristic common to other death substrates (Cryns et al., 1996). 


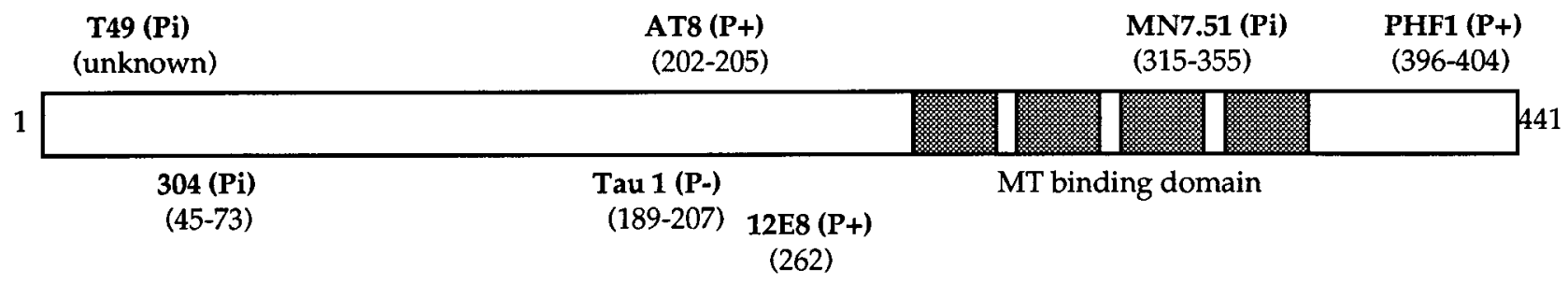

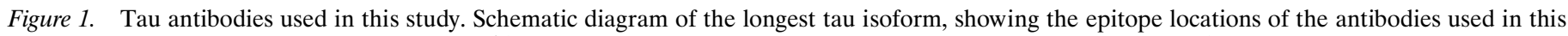

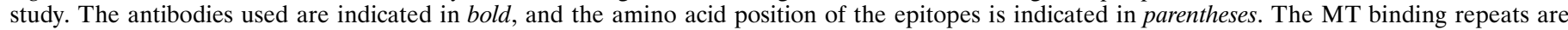

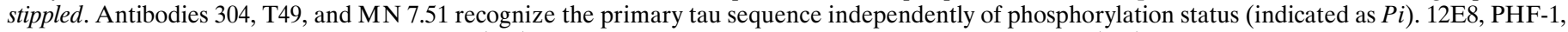
and AT8 recognize phosphorylated epitopes $(P+)$, whereas Tau-1 binds to a dephosphorylated epitope $(P-)$.

Inhibition of apoptosis using a number of known anti-apoptotic reagents (D'Mello et al., 1993; Galli et al., 1995; Vitolo et al., 1998) (Fig. 2B) results in disappearance of the $17 \mathrm{kDa}$ band in direct proportion to the anti-apoptotic efficacy of the reagent in this system. Forskolin and IGF-1, for example, are powerful inhibitors of apoptosis and completely abolish the $17 \mathrm{kDa}$ band, whereas $\beta$ NAD (Vitolo et al., 1998) and adenosine and PACAP-38 (Villalba et al., 1997) are less effective, and a residual amount of the $17 \mathrm{kDa}$ band can be seen (Fig. $2 B$ ).

In an attempt to localize this fragment within tau, we used the phosphorylation-independent antibodies 304, MN7.51, and T49 (Fig.1), which recognize sites flanking those recognized by Tau-1. We found a general reduction in the amount of tau present, but the $17 \mathrm{kDa}$ band was not visualized by these antibodies (data not shown). This indicates that the $17 \mathrm{kDa}$ fragment is found within the 232 amino acids between 73 and 315 (the limits of the epitopes recognized by 304 and MN7.51).

\section{During apoptosis, a reduction in tau binding occurs simultaneously with the disruption of the microtubule network}

The effect of this cleavage on the ability of tau to associate with microtubules was investigated by fractionating extracts from cerebellar granule cells undergoing apoptosis into Triton X-100soluble and -insoluble (cytoskeletal or MT bound) fractions and probing with mAbs recognizing tau, tubulin, and $\beta$-actin. Results of these experiments are shown in Figure 3 in terms of Western blots and in Figure 4 as densitometric analysis of the same experiments. As can be seen in Figure $3 A, F$, the $17 \mathrm{kDa}$ fragment recognized by Tau- 1 is recovered predominantly in the soluble cellular fraction from apoptotic cells, indicating that this fragment is unable to bind (or loosely binds) to microtubules. In addition to the presence of the $17 \mathrm{kDa}$ fragment in the soluble fraction, it can be seen that the amount of full length tau bound to microtubules recognized by Tau- 1 shows, after a peak detectable at $3 \mathrm{hr}$, a progressive decrease with the onset of apoptosis [35\% of control levels after $12 \mathrm{hr}$ (Figs. $3 A, 4 A$ )], whereas that in the soluble fraction (Figs. $3 F, 4 C$ ), on the contrary, increases by $>70 \%$. To investigate whether the reduction in tau bound to MTs (Fig. $3 A$ ) is absolute or attributable to a change in phosphorylation status, the same gels shown in Figure $3 A$ were stripped and reprobed with MN7.51 (Fig. $3 B$ ), a mAb that recognizes tau independently of its phosphorylation status. This shows, consistent with the Tau- 1 results, that there is a significant decrease of MT-bound tau by $12 \mathrm{hr}[>90 \%$ (Fig. $4 A$ )], confirming that this change reflects a reduction in total microtubule-bound tau and not a modification in phosphorylation status. A similar trend is seen with T49, which recognizes the $\mathrm{N}$ terminus of tau (Figs. $3 C$, $4 A$ ). These changes in microtubule-bound tau are accompanied by disruption of the microtubule network, manifested by a reduction in the amount of $\alpha$-tyrosinylated tubulin in the cytoskeletal fraction (Fig. 3D) and its increase in the soluble pool (Figs. 3I, 4B)

As mentioned above, although the general trend is for the levels of MT-bound tau to reduce with apoptosis, there is a consistent increase seen early in the process (at $3 \mathrm{hr}$ ). In fact, there is a strong correlation between the levels of MT-bound tau (Fig. 3A-C) and the amount of polymerized tubulin (Fig. 3D), suggesting a causal relationship between the two, which is bestillustrated in Figure $4 A, B$.

That these changes in tau and tubulin levels are not consequences of different gel loadings is shown by the levels of $\beta$-actin, which remains constant throughout (Figs. 3E, 4A). This also shows that the dramatic reduction in the cytoskeletal content of tau was not caused by an induction of general proteolysis, as also confirmed by Coomassie staining of gels (data not shown). Hence it is unlikely that the proteolysis of tau is attributable to gross changes in the total amount of cytoskeleton proteins.

Interestingly, the increase in Tau-1-reactive tau in the soluble fraction is accompanied by a decrease in full length tau (30-70\% at $12 \mathrm{hr}$ ), as shown by the staining patterns with MN7.51 and T49 (Figs. $3 G, H, 4 B$ ), indicating that the total amount of soluble tau decreases with apoptosis and that the degree of phosphorylation at the Tau- 1 site is reduced.

Figure $3 G$ also shows that there is a reduction in the size of tau $(\sim 5 \mathrm{kDa})$ recognized by MN7.51 that is not seen by T49 (Fig. $3 H$ ). Because both of these mAbs recognize phosphorylationindependent epitopes, this reduction in size is attributable not to changes in phosphorylation but to loss of the T49 epitope located at the $\mathrm{N}$ terminus (Mawal-Dewan et al., 1994) in a large fraction (70\%) of the tau molecules. This may be a precursor to the 17 $\mathrm{kDa}$ fragment, which by $12 \mathrm{hr}$ accounts for $40 \%$ of total Tau-1recognized tau (Figs. $3 F, 4 C$ ), a figure similar to the percentage of apoptotic cells. It is difficult, however, to assess what proportion of total tau this represents, because of the requirement that this antibody has for the dephosphorylated epitope.

\section{The cleavage of tau is not a consequence of a destabilization of microtubules}

To investigate whether tau cleavage was a consequence of microtubule destabilization, we treated cerebellar granule cells with 1 $\mu \mathrm{M}$ colchicine, a drug that causes apoptosis by disassembly of the microtubule network (Bonfoco et al., 1995). We found that this treatment did not lead to tau cleavage until $24 \mathrm{hr}$ of apoptosis, by which time the number of apoptotic cells reached $70 \%$ (Fig. 5A). That tau is not cleaved merely as a result of disruption of microtubules was further confirmed by treating cells undergoing apoptosis (after potassium and serum deprivation) with taxol (at 
(A)

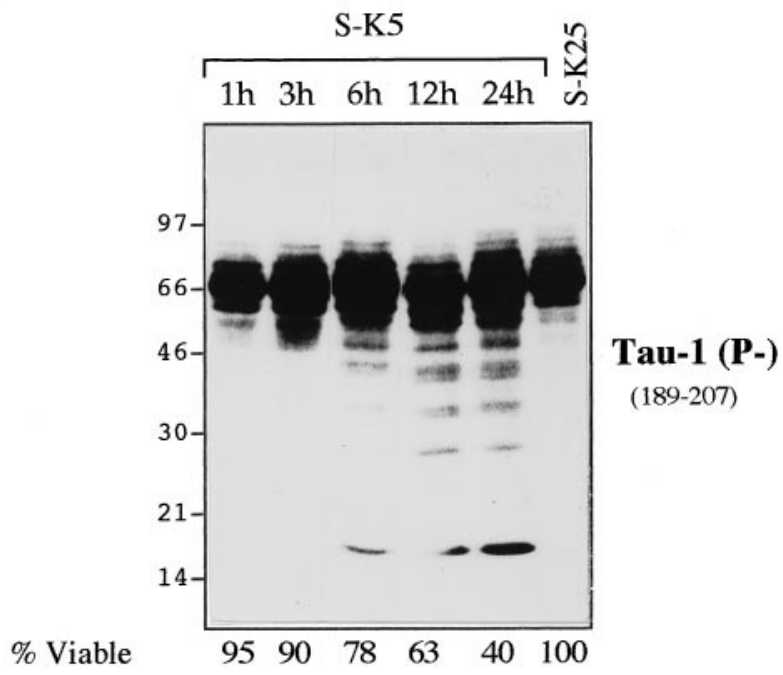

(B)

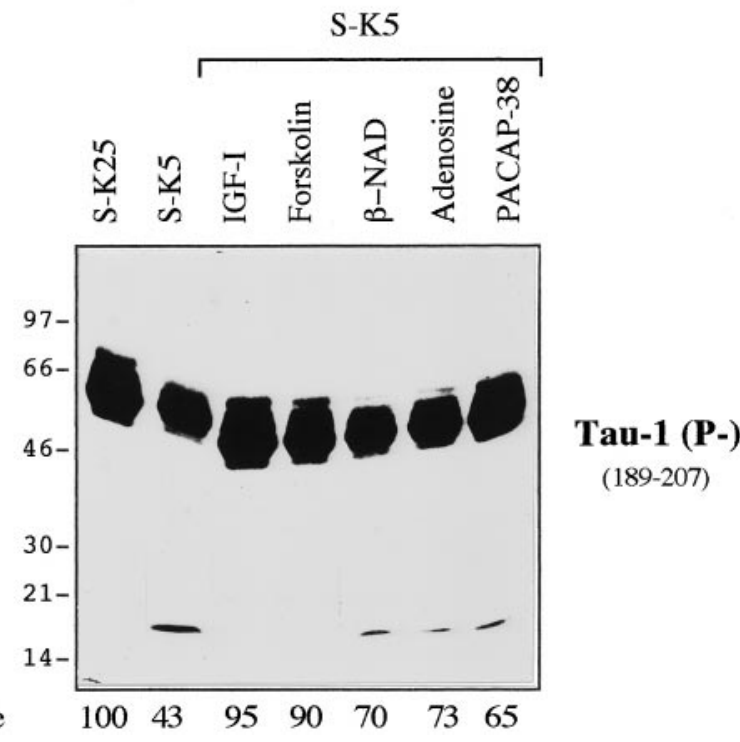

Figure 2. Specific and rapid cleavage of tau during the apoptosis of CGC induced by potassium and serum deprivation. $A$, CGCs were washed and maintained in high-potassium and serum-free medium (S-K25) for $24 \mathrm{hr}$ or switched to K5 and serum-free BME (S-K5). At 1, 3, 6, 12, and $24 \mathrm{hr}$ after the switch, $25 \mu \mathrm{g}$ of total cellular protein was analyzed by Western blot using the mAb Tau-1 (see Fig. 1). For each time point, the corresponding viability was determined as described in Materials and Methods. $B$, Effect of various antiapoptotic agents on the generation of the Tau-1recognized $17 \mathrm{kDa}$ fragment. Granule cell neurons were maintained in S-K25 or subjected to S-K5 alone or in the presence of IGF-1 $(25 \mathrm{ng} / \mathrm{ml})$, forskolin $(10 \mu \mathrm{M})$, nicotinamide adenine dinucleotide $(\beta-N A D)(100 \mu \mathrm{M})$, adenosine $(100 \mu \mathrm{M})$, or pituitary adenylate cyclase-activating polypeptide (PACAP)-38 (100 nM) for $16 \mathrm{hr}$. The corresponding viability for each lysate was determined as described in Material and Methods and reported below the figure.

concentrations ranging from 0.1 to $20 \mu \mathrm{M}$ ), a drug that polymerizes and stabilizes microtubules, although it is unable to inhibit apoptosis under these conditions. We noted that under this condition the production of the $17 \mathrm{kDa}$ fragment still occurs (Fig. 5B).

\section{Apoptosis changes the phosphorylation state of tau}

Tau phosphorylation has been reported to affect its susceptibility to proteases (Litersky and Johnson, 1992; Wang et al., 1995) as well as its ability to bind to microtubules (Biernat et al., 1993; Lindwall and Cole, 1984). To investigate the effect of apoptosis on tau phosphorylation we used a number of $\mathrm{mAbs}$ that recognize phosphorylated epitopes (Fig. 1). Figure $6 A, B$ shows that there is a decrease in the phosphorylation of those epitopes recognized by the mAbs $12 \mathrm{E} 8$ and AT8 ( $80-90 \%$ by $12 \mathrm{hr}$ ). PHF- 1 also shows a decrease in phosphorylation, but not all PHF-1-immunoreactive tau isoforms are decreased similarly: the smaller $(45-55 \mathrm{kDa})$ fragments decrease by $80-90 \%$, whereas the larger $(68 \mathrm{kDa})$ are scarcely touched (Fig. 6C). This is reminiscent of the A68 fragment found in $\mathrm{AD}$ (Lee et al., 1991). These $68 \mathrm{kDa}$ tau isoforms (like their AD counterparts) are not able to bind the microtubules, because they are not recovered in the insoluble fraction extract (data not shown).

This decrease in tau phosphorylation is probably attributable to two factors: an absolute reduction in the amount of tau caused by the cleavage described above as well as a parallel reduction in phosphorylation. This is a finding confirmed for the site recognized by the antibodies Tau- 1 and AT8. Tau- 1 recognizes tau nonphosphorylated at Ser 186,189,190 and Ser 193 (Szendrei et al., 1993), whereas AT8 recognizes tau phosphorylated at Ser 193 and Thr 196; as such they can be considered relatively complementary (Burack and Halpain, 1996). As can be seen by comparing Figure 2 with Figure $6 A$, the increase in the immunoreactivity of Tau-1 is associated with a complete loss of AT8 immunoreactivity.

\section{Cellular redistribution of tau during apoptosis}

Because not all cells undergo apoptosis simultaneously in this preparation, the biochemical changes in tau described above reflect changes in a population of cells, each cell being in a different phase of apoptosis. To examine the effects of apoptosis on individual cell, immuofluorescence with Hoechst 33258 (which stains the nucleus), MN7.51, and Tau-1 was performed (Fig. 7). It can be seen that only in those cells undergoing apoptosis, recognizable as those having a small condensed or fragmented nucleus strongly stained with Hoechst (Fig. 7, white arrows), MN7.51 staining shows a generalized decrease of tau (Fig. 7, compare $A, C$ ), whereas Tau-1 staining increases, becoming concentrated in the cell body and markedly reduced in neurites compared with that in control cells (Fig. 7, compare $A^{\prime}, C^{\prime}$ ). This difference in staining patterns is difficult to explain purely in terms of changes in tau phosphorylation and is more likely to be caused by microtubule depolymerization as result of tau degradation into smaller fragments, one of which (that recognized by Tau-1) remains intact and is redistributed from neurites to perikarya, whereas that recognized by MN7.51 is progressively degraded.

These changes in tau immunostaining are accompanied by a generalized disappearance of the microtubule network (data not shown), indicating that destruction of the microtubule network and a reduction of tau levels are essential components of the apoptotic process in neurons.

\section{Identification of the proteases responsible for producing the $17 \mathrm{kDa}$ fragment}

Having demonstrated that tau cleavage is an early event in apoptosis, we next examined the sensitivity of this cleavage to different protease inhibitors. To this aim, these compounds were added to cerebellar granule cells before, or simultaneously with, the induction of cell death. As shown in Figure 8A, the greatest 
Detergent resistant fraction

\begin{tabular}{|llll|}
\hline (A) (B) & (C) & (D)
\end{tabular}

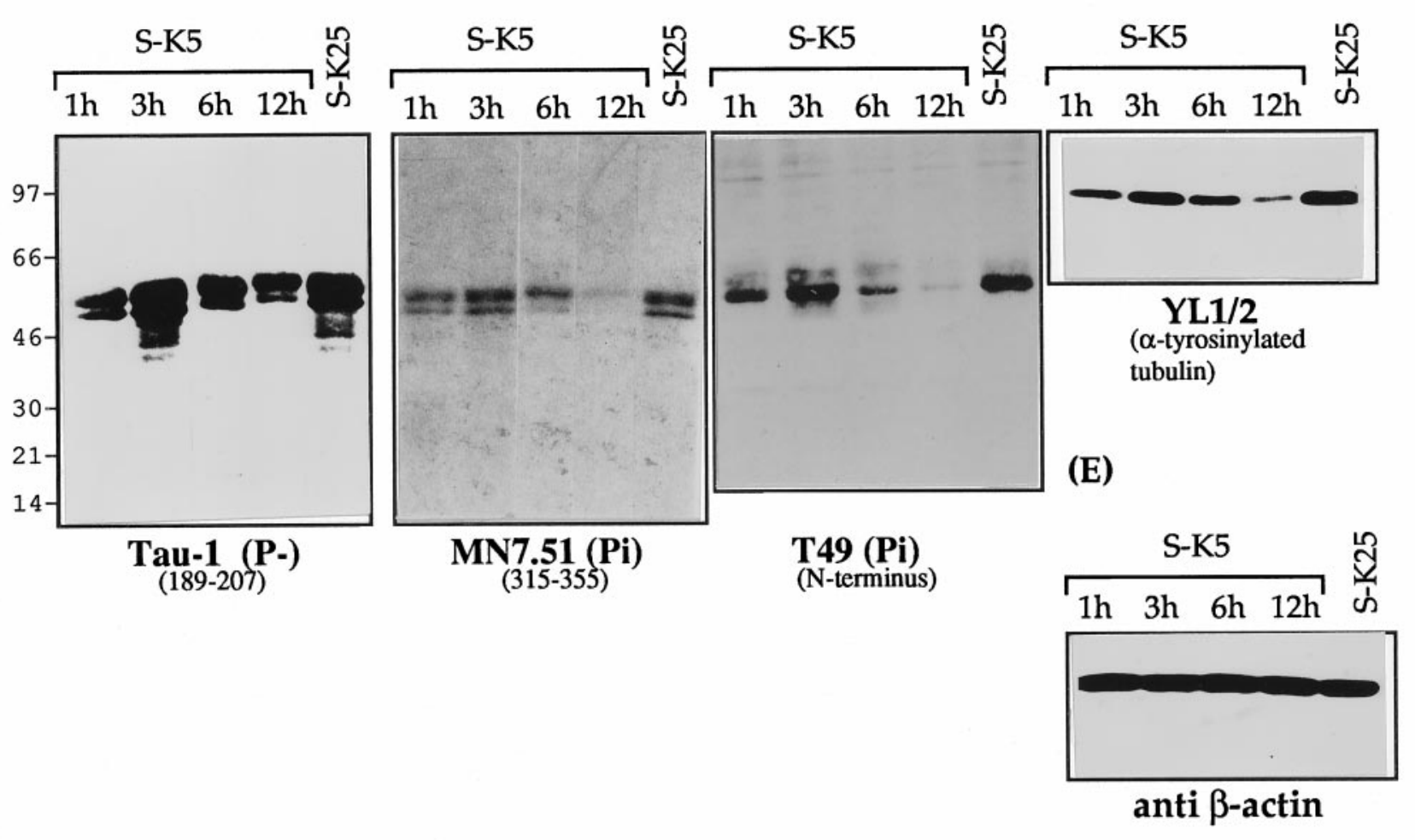

Soluble fraction

(F)

(G)

(H)

(I)
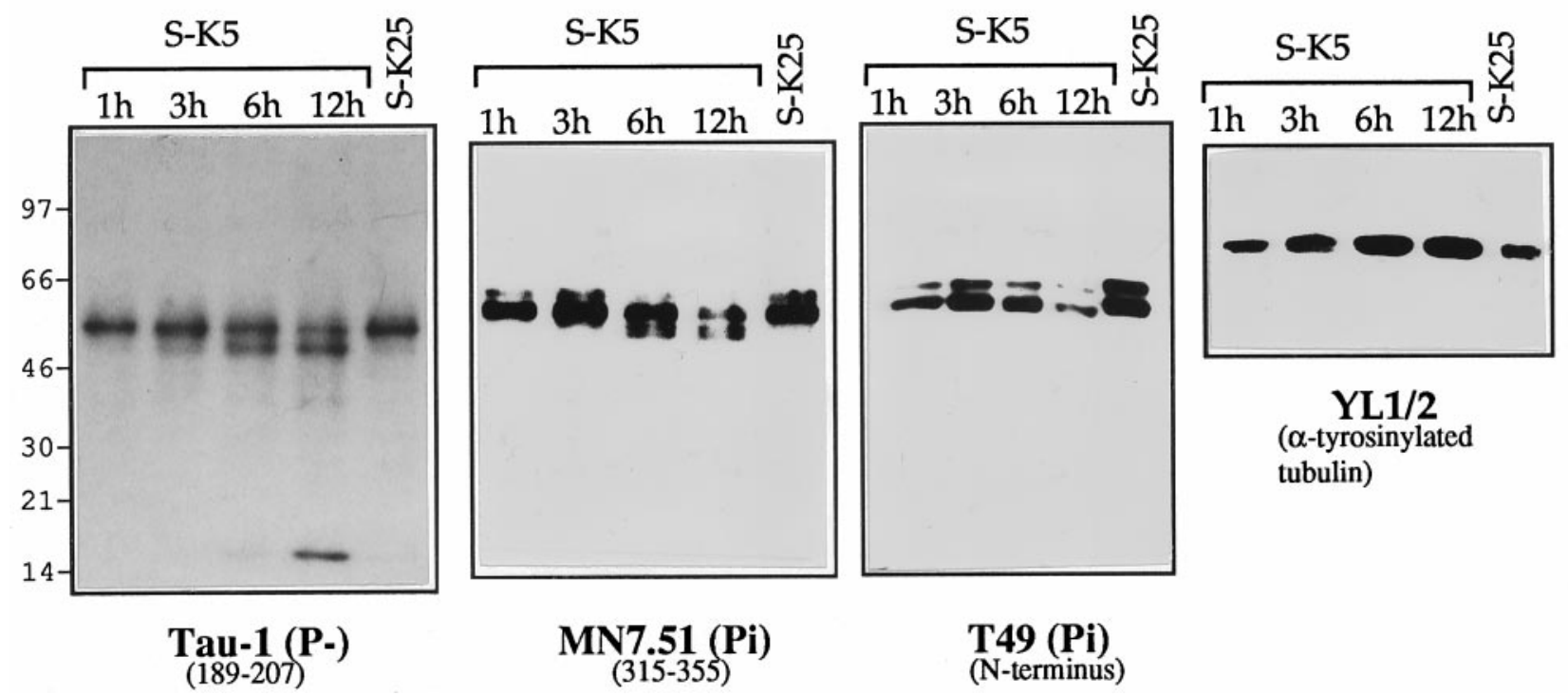

Figure 3. The $17 \mathrm{kDa}$ fragment is unable to bind to microtubules: disassembly of the microtubule network during apoptosis. Western blot analyses of cytoskeletal protein in cerebellar granule neurons undergoing apoptosis. Shown are Western blots of detergent-resistant $(A, E)(30 \mu \mathrm{g})$ and soluble $(F$, $I)$ fractions $(20 \mu \mathrm{g})$ after Triton X-100 extraction as described in Material and Methods. Cerebellar granule neurons were cultured in the absence of serum and high potassium $(S-K 25)$, or the absence of serum and low potassium $(S-K 5)$. Western blot analysis was performed with the monoclonal antibodies Tau-1 $(A, F)$ (specific for tau dephosphorylated at 189-207), MN $7.51(B, G)$ (phosphorylation independent epitope in the third microtubule domain), T49 $(C, H)$ (N-terminal epitope), YL 1/2 $(D, I)$ (against $\alpha$-tyrosinylated tubulin), and mAb to $\beta$-actin $(E)$. 
(A)

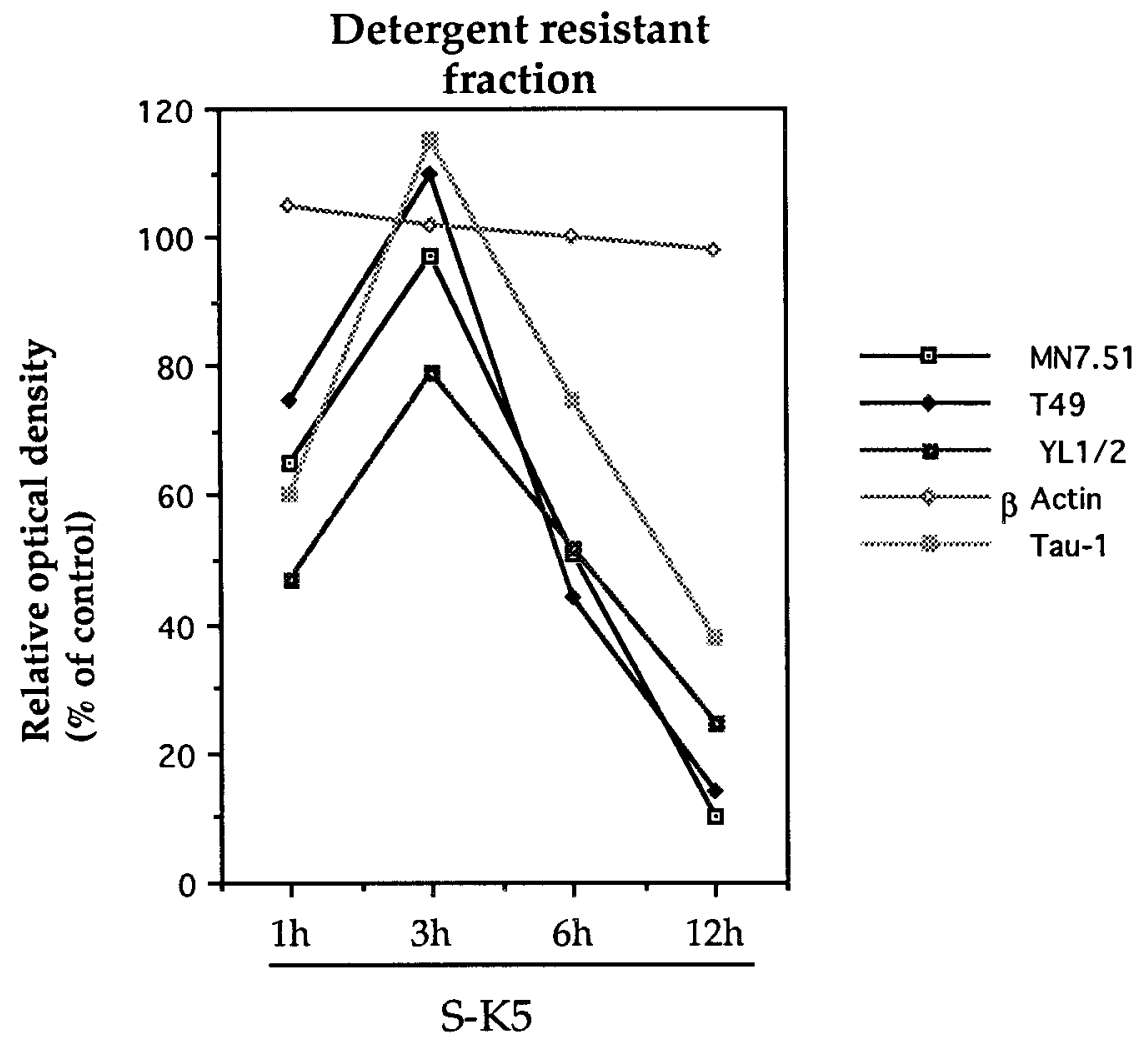

(B)

(C)
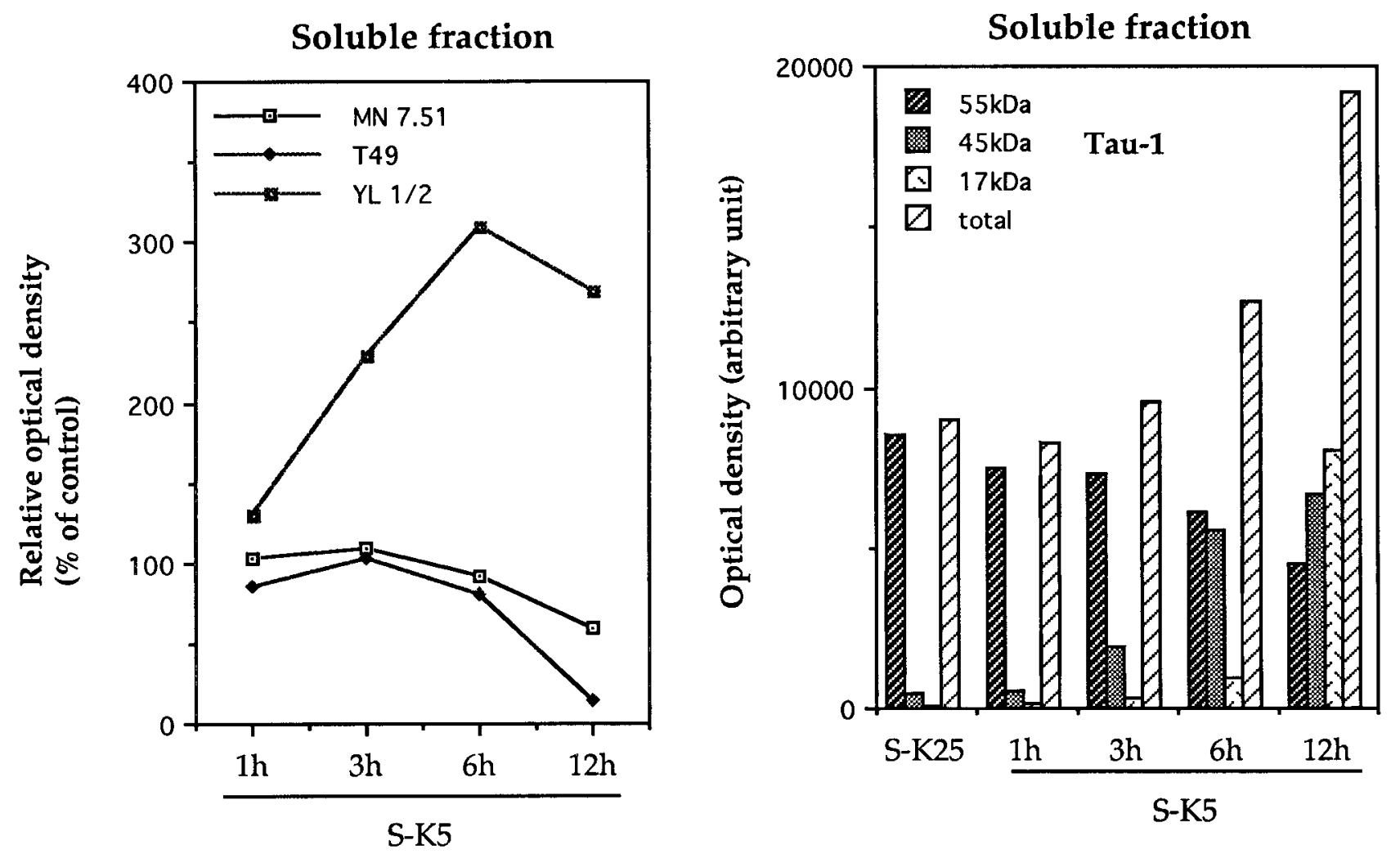

Figure 4. Densitometric analysis of Western blots reported in Figure 3. Tau, $\beta$-actin, and $\alpha$-tyrosinylated tubulin immunoreactivity on detergentresistant fractions $(A)$ and soluble fractions $(B)$ are expressed as percentages of control cells ( $\mathrm{S}-\mathrm{K} 25$ for $12 \mathrm{hr}$ ), where control cells have been given a value of 100. Results shown are representative of at least two experiments. $C$, Densitometric analysis of the different bands recognized by Tau-1 in Figure $3 G$. The absolute scanning values are given for 17,45 , and $55 \mathrm{kDa}$ fragments. 

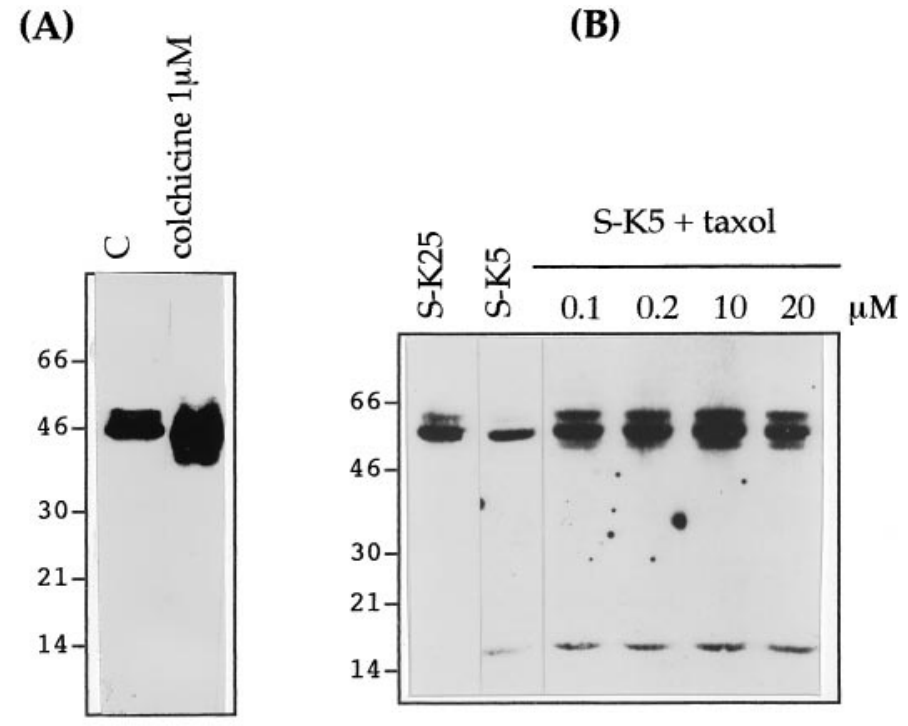

Tau-1 (P-)

(189-207)

Figure 5. Effect of colchicine and taxol on tau cleavage during apoptosis. $A$, Cultured cerebellar granule neurons were exposed to $1 \mu \mathrm{M}$ colchicine for $24 \mathrm{hr}$ or maintained in $\mathrm{S}+\mathrm{K} 25$ [control $(C)$ ] or induced to undergo apoptosis by serum and potassium deprivation in the presence of taxol $0.1-20 \mu \mathrm{M}$ for $12 \mathrm{hr}$. $B$, Total cellular proteins were extracted and analyzed by SDS-PAGE (7-15\%) (15 $\mu \mathrm{g}$ of protein per lane in Fig. $4 A$ and $25 \mu \mathrm{g}$ per lane in Fig. 4B), electroblotted, and analyzed with mAb Tau-1.

inhibition of the formation of the $17 \mathrm{kDa}$ fragment is seen with inhibitors that block either calpain and proteasomes (ALLM, ALLN), calpain and cathepsin (E64d), or calpain alone (leupeptin); ALLN and ALLM reduce the intensity of this band by $>95 \%$, whereas protease inhibitors with different specificities have no effect on the formation of the $17 \mathrm{kDa}$ fragment in apoptotic cells (Fig. 8B). This suggests that the protease in cerebellar granule cells responsible for this activity is calpain. These calpain inhibitors, in addition to reducing the intensity of the $17 \mathrm{kDa}$ band, also caused an increase in full length tau and bands 5-10 kDa smaller than full length tau. These are probably caused by an accumulation of tau partially cleaved by other protease(s) as well as an increase in the amount of dephosphorylated tau recognized by Tau- 1 .

Further confirmation of calpain as the protease responsible for this tau cleavage was obtained by in vitro cleavage of both purified tau and tau derived from cerebellar granule cell (CGC) extracts, using purified calpain. As can be seen in Figure $8 C$, a band with a mobility of $17 \mathrm{kDa}$, identical to that seen during apoptosis, and whose appearance can be inhibited by ALLN, is obtained with in vitro cleavage of both cerebellar cell extracts and purified tau. Figure $8 C$ also demonstrates that partial cleavage of tau could be obtained by calcium activation of endogenous calpain (control 2) as well as an increase in tau dephosphorylation caused by activation of endogenous phosphatases.

CGC induced to undergo apoptosis by serum and potassium deprivation were also treated with the caspase inhibitors YVADcho (caspase-1), z-DEVD-fmk (caspase-3), or z-VAD-fmk (general caspase) (for review, see Cohen, 1997). Of these, z-VAD-fmk reduced the intensity of the $17 \mathrm{kDa}$ band by $80-90 \%$ and
z-DEVD-fmk reduced it by 35\% (Fig. 9B), whereas YVAD-cho had no effect (Fig. 9A,B).

Of the caspases, caspase-3 is that involved in the cleavage of most apoptotic substrates (Cohen, 1997). To find out whether caspase-3 was also able to cleave tau, in vitro translated tau was treated with this protease. As seen in Figure $9 C$, caspase-3 reduces the size of tau by $\sim 5 \mathrm{kDa}$, this reduction being inhibited by AcDEVD-cho, a specific caspase-3 inhibitor. Tau is known to migrate anomolously in PAGE, and this result is consistent with the cleavage of either one or both of the terminal potential caspase-3 sites reported in Figure 10. The potential internal site identified within the fourth repeat at 341 is resistant (Fig. 10). Interestingly, this in vitro cleavage of tau by caspase- 3 yields bands similar in size to those seen when apoptotic granules are treated with calpain inhibitors (Fig. $8 A$ ).

This finding indicates that tau is a substrate for both calpain and caspase- 3 and that cleavage with both of these proteases appears to occur during apoptosis in this system.

\section{DISCUSSION}

In this study we show that when apoptosis is induced in CGC by deprivation of $\mathrm{K}^{+}$and serum, tau is cleaved to a $17 \mathrm{kDa}$ residual fragment. The appearance of this fragment is dependent on the induction of apoptosis, because inhibition of this process blocks its appearance; it is specific, because neither tubulin nor actin undergo similar changes in this model of apoptosis, and it is proportional to the duration of apoptosis.

The $17 \mathrm{kDa}$ fragment is unable to bind to microtubules (Fig. $3 A$ ), and its appearance is also associated with a reduction in the amount of full length microtubule-bound tau. This is strongly correlated with a dramatic destabilization of the microtubule network, as shown by a decrease in the amount of polymerized tubulin and an increase in the level of soluble tubulin monomers (Fig. 3D,H). Our data suggest that relative changes in tau phosphorylation could also contribute to microtubule breakdown. In particular, Figure $6 C$ shows that the levels of the $68-69 \mathrm{kDa}$ tau isoforms recognized by PHF-1 are not altered during apoptosis. As a result, the densitometric ratio between this form $(68-69 \mathrm{kDa})$ and the smaller $(50-55$ $\mathrm{kDa}$ ) changes from 0.5 (in control cells) to 3.0 (in $\mathrm{K}^{+}$-deprived cells), indicating that as apoptosis progresses, the bulk of soluble tau becomes incompetent to bind tubulin. This observation is in agreement with data in the literature (Lee et al., 1991) as well as our finding that these isoforms of phosphorylated tau $(68-69 \mathrm{kDa})$ were never recovered in the cytoskeleton fraction, indicating that they do not, or that they loosely bind MTs (data not shown). One reason for the accumulation of such isoforms is likely to be their resistance to protease digestion (Litersky and Johnson, 1992; Wang et al., 1995).

An examination of the sequence of tau reveals the presence of a number of potential calpain cleavage sites (Fig. 10). It is striking that complete cleavage of the longest tau isoform by calpain would be predicted to yield a fragment of $18.6 \mathrm{kDa}$, very similar to that found. Cleavage of all the alternatively spliced forms of tau would be expected to yield two further bands of 12.8 and $15.7 \mathrm{kDa}$ (Fig. 10). In other experiments (data not shown), three fragments can be seen. These data, coupled with the fact that the appearance of this fragment can be inhibited by calpain inhibitors and an identically sized fragment can be produced by calpain in vitro, indicate that calpain is involved in cleavage of tau in this model of neuronal apoptosis. Recently it has been reported that calpains are 
(A)

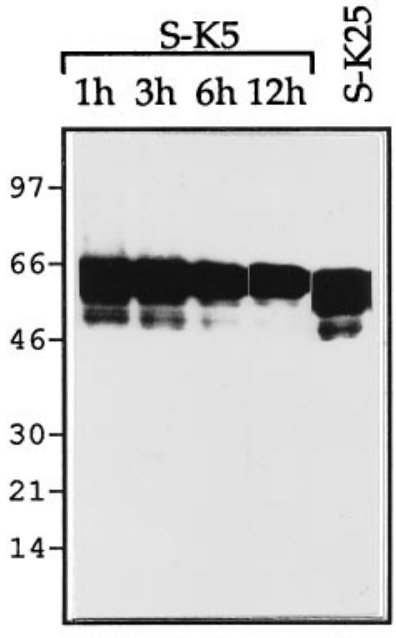

PHF-1 (P+) (396-404)

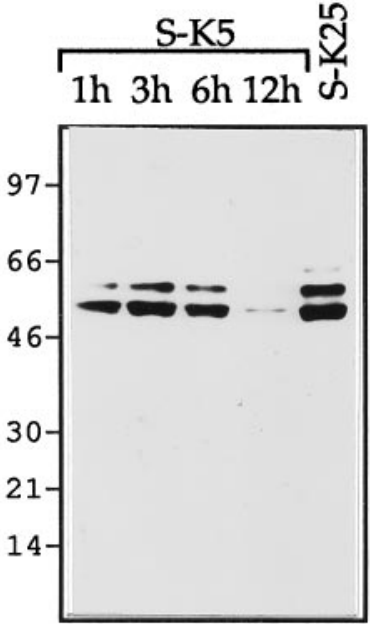

12E8 (P+) (262)

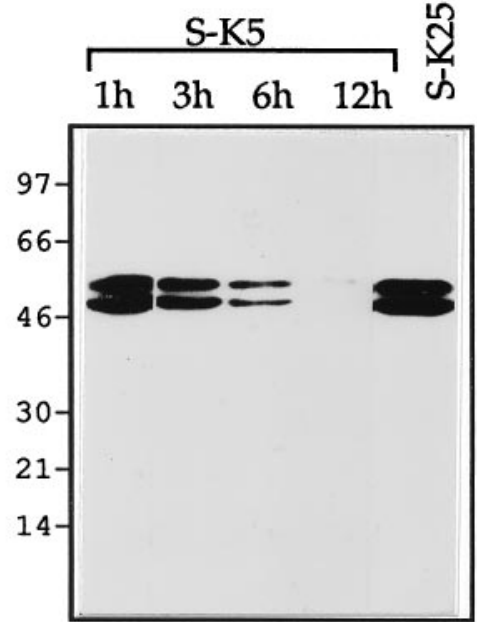

AT8 (P+)

(202-205)

(B)

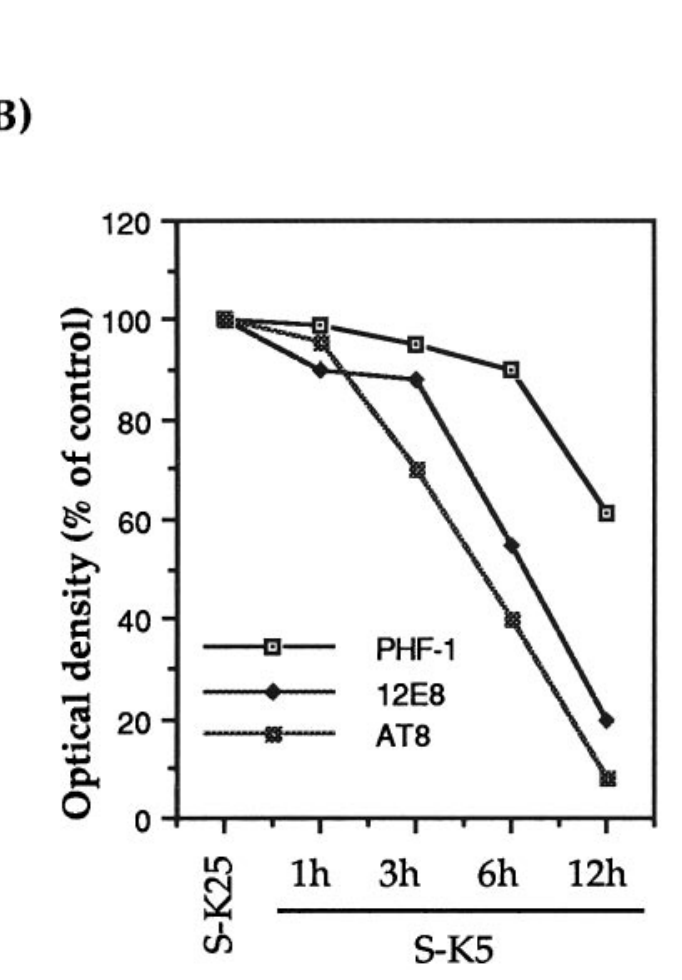

(C)
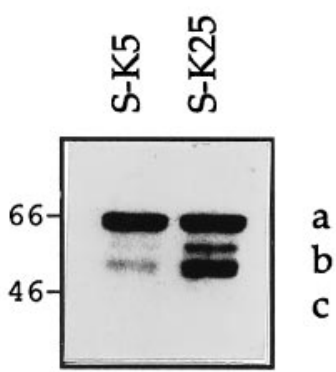

(D)
PHF-1

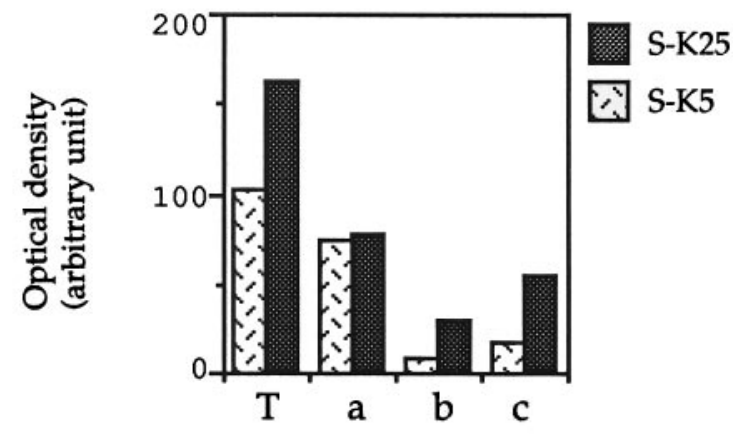

Figure 6. Modulation of tau phosphorylation during apoptosis. A, Granule neurons were either maintained in high $\mathrm{K}^{+}$medium (S-K25) for 12 hr or exposed to low $\mathrm{K}^{+}$medium (S-K5) for various lengths of time. Total cellular proteins were extracted and analyzed by SDS-PAGE (7-15\%) (15 $\mu \mathrm{g}$ of protein per lane), electroblotted, and analyzed with the mAbs PHF-1, 12E8, and AT8. B, Densitometric analysis of tau immunoreactivity expressed as percentages of control cells (untreated for $12 \mathrm{hr}$ ) where control cells have a value of 100 , indicated for the different mAbs. $C$, PHF-1 immunoblotting showing the reduction of the 50-55 kDa isoforms and $(D)$ their densitometric evaluation. Results are representative of at least two experiments. In Figure $5 D, T$ indicates the total PHF-1 immunoreactivity.

activated in CGC undergoing apoptosis (Nath et al., 1996) and in other models of apoptosis (Sarin et al., 1994; Villa et al., 1998) as well as in neuronal death associated with ischemia (Neumar et al., 1996) and some neurodegenerative diseases (Saito et al., 1993). The identification of tau as substrate for calpain during apoptosis suggests that calpain-mediated proteolysis may play an important role in the dismantling of cytoskeletal architecture associated with apoptosis. It is noteworthy in this respect that levels of calpain activity have also been shown to be increased in AD (Saito et al., 1993). 

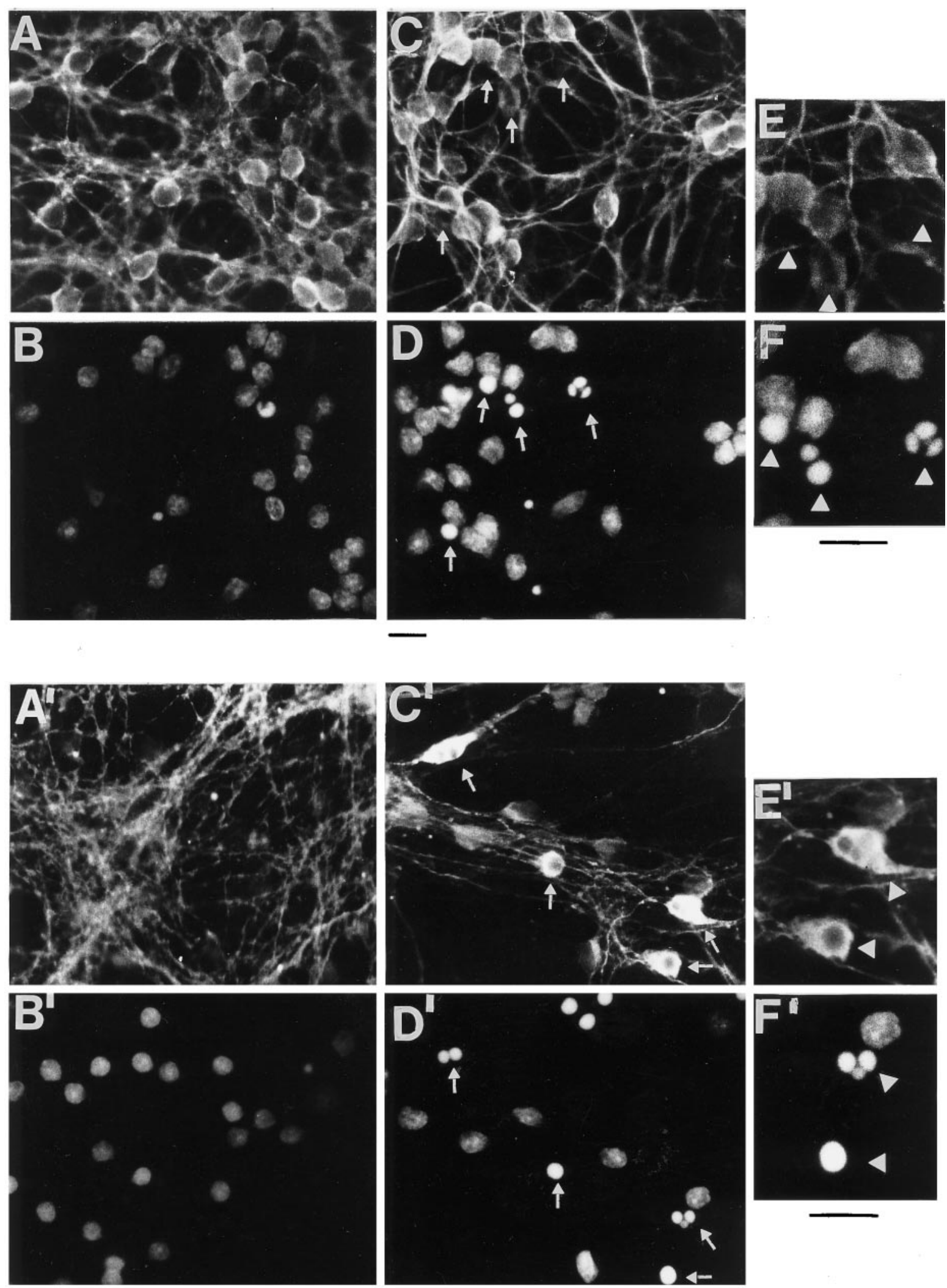

Figure 7. Immunofluorescence studies showing the effect of apoptosis on tau immunostaining. Shown is immunofluorescence of control cultures $\left(A, A^{\prime}\right.$, $E$ ) and cultures exposed to $\mathrm{K}^{+}$and serum deprivation for $6 \mathrm{hr}\left(C, C^{\prime}, E^{\prime}\right)$. Nuclei were stained with Hoechst $33258\left(B, B^{\prime}, D, D^{\prime}, F, F^{\prime}\right)$, and tau was immunostained with mAb MN $7.51(A, C, E)$ or mAb Tau-1 $\left(A^{\prime}, C^{\prime}, E^{\prime}\right)$. Few or no apoptotic nuclei are seen in control cultures $\left(B, B^{\prime}\right)$. In $D$ and $D^{\prime}$, apoptotic nuclei, recognizable as those having a round shape and condensed or fragmented chromatin, are not immunostained or are minimally immunostained with MN $7.51(C)$, whereas they are strongly stained with Tau-1 $\left(C^{\prime}\right)$. Big arrows indicate immunostaining with MN 7.51 and Tau-1 and their corresponding nuclei in the magnification picture $\left(E, F, E^{\prime}, F^{\prime}\right)$. Scale bars, $7 \mu \mathrm{m}$. 
(A)

(B)

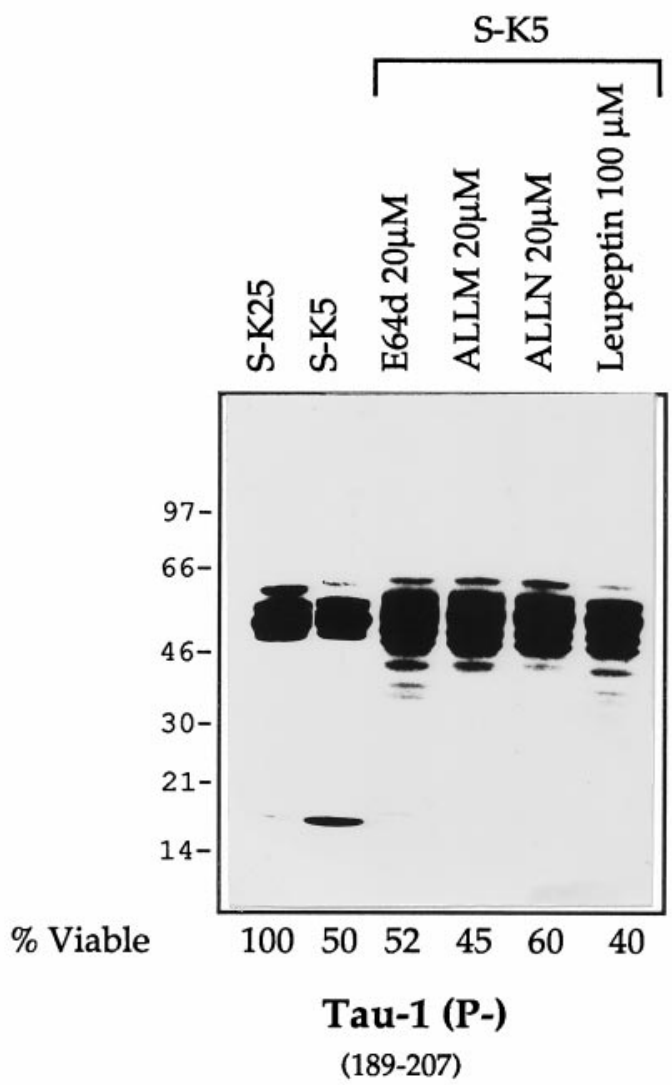

Treatment

\section{$\mathrm{S}-\mathrm{K} 5$}

+ALLM $20 \mu \mathrm{M}$

+ALLN $20 \mu \mathrm{M}$

$+\mathrm{E} 64 \mathrm{~d} 20 \mu \mathrm{M}$

+Leupep $100 \mu \mathrm{M}$

+ PMSF $100 \mu \mathrm{M}$

+Pepstatin $50 \mu \mathrm{M}$

+AESFB $500 \mu \mathrm{M}$

+YVAD-CHO $100 \mu \mathrm{M} \times 2$

+DEVD-fmk $150 \mu \mathrm{M} \times 2$

$+\mathrm{VAD}-\mathrm{fmk} \quad 100 \mathrm{mM} \times 2$
$17 \mathrm{kDa}$ optical density (\% of S-K5)

100
9
8
10
7
100
95
97
100
65
20

(C)

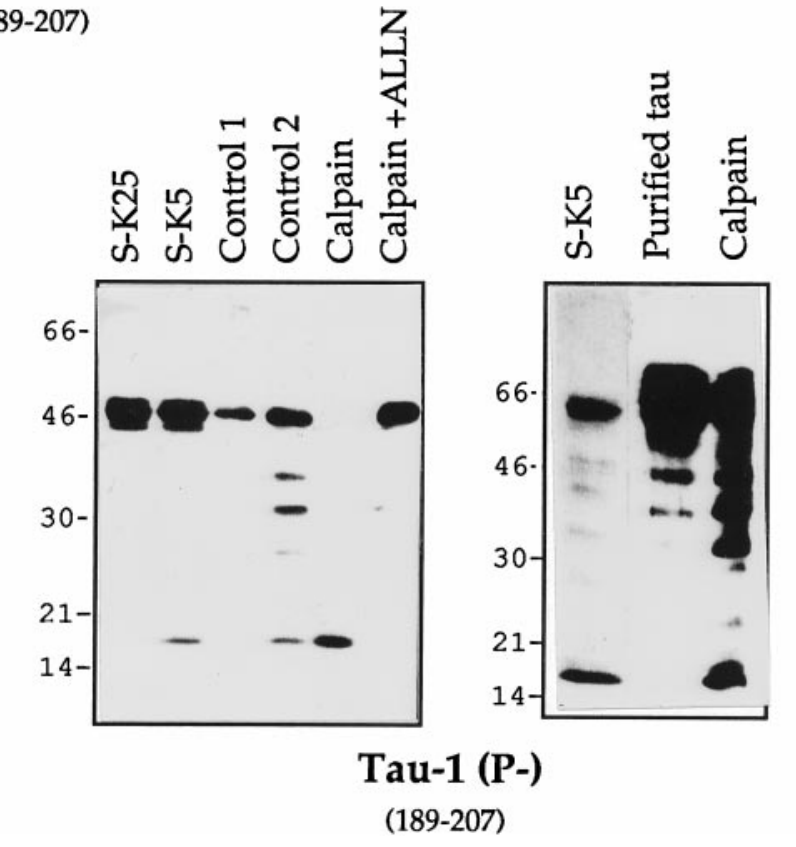

Figure 8. Tau proteolysis profiles during apoptosis with different protease inhibitors. $A$, Total protein extracts $(25 \mu \mathrm{g})$ of control cells (S-K25) and apoptotic cerebellar granule cells (S-K5) in the absence or presence of various calpain inhibitors: ALLN $(20 \mu \mathrm{M})$, ALLM (20 $\mu \mathrm{M})$, E64d (20 $\mu \mathrm{M})$, and leupeptin $(100 \mu \mathrm{M})$. All of the inhibitors were added $2 \mathrm{hr}$ before and at the time of apoptosis induction. The lysates were resolved on a 7-15\% gel and probed with mAb Tau-1. The corresponding viability for each lysate was determined as reported in Material and Methods. $B$, Densitometric values (\% of $\mathrm{S}-\mathrm{K5}$ ) of the $17 \mathrm{kDa}$ fragment after treatment with different protease inhibitors. $C$, In vitro cleavage of tau by calpain. S-K25, Control cells in $25 \mathrm{~mm}$ potassium; S-K5, cells induced to undergo apoptosis in $5 \mathrm{~mm}$ potassium. Control 1, Untreated cellular extracts incubated on ice. Control 2, Cellular extracts incubated with $5 \mathrm{~mm} \mathrm{Ca}^{2+}$ at $30^{\circ} \mathrm{C}$ for $10 \mathrm{~min}$ without calpain. Limited proteolysis of tau present in Control 2 occurs as a result of the activation of endogenous calpain by calcium. Calpain, Granule cell protein extract $\left(20 \mu \mathrm{g}\right.$ of protein) or purified bovine tau treated with $(0.5 \mu \mathrm{g})$ calpain at $30^{\circ} \mathrm{C}$ for $10 \mathrm{~min}$; Calpain + ALLN, as calpain treated with ALLN $20 \mu \mathrm{M}$. The samples were analyzed on Western blot with mAb Tau-1. 
(A)

(B)
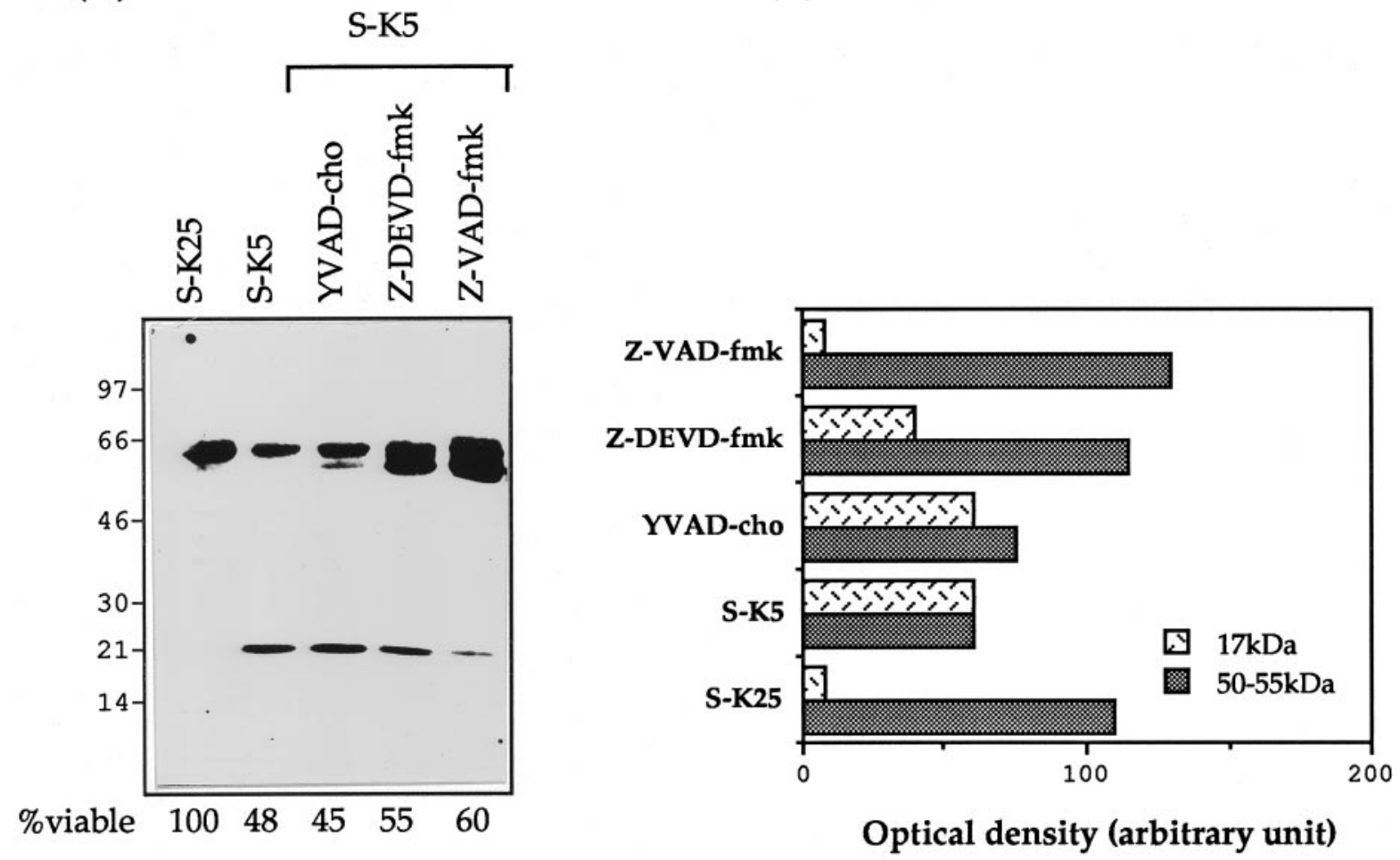

Tau-1 (P-)

(189-207)

(C)

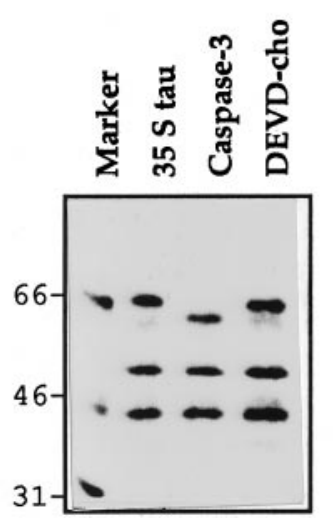

Figure 9. Effect of caspase inhibitors on proteolysis of tau. $A$, Total protein extracts $(25 \mu \mathrm{g})$ of control cells (S-K25) and apoptotic cerebellar granule cells (S-K5) in the presence or absence of various caspase inhibitors, YVAD-cho (100 $\mu \mathrm{M})$, ZDEVD-fmk (150 $\mu \mathrm{M})$, and ZVAD-fmk (100 $\mu \mathrm{M})$, for 16 $\mathrm{hr}$. All the inhibitors were added $2 \mathrm{hr}$ before, and at the time of, apoptosis induction. The corresponding viability for each lysate was determined as reported in Materials and Methods. $B$, Densitometric analysis of the $17 \mathrm{kDa}$ and the $50-55 \mathrm{kDa}$ Tau- 1 bands reported in $A$, expressed in densitometric units. Results are representative of at least two experiments. $C$, In vitro translated tau treated with bacterial extracts containing caspase-3. DEVD-cho is a specific inhibitor of caspase 3 .

In addition, tau also has three potential caspase- 3 sites [DXXD (Cohen, 1997)] at positions 25, 341, and 421, each of which is close to a potential calpain site (11/44, 340, and 394) (Fig. 10). Cleavage of the $\mathrm{N}$ - and $\mathrm{C}$-terminal caspase sites would be expected to lead to a reduction in the size of tau of $2-4 \mathrm{kDa}$. This is similar to the size reduction seen with MN751 during apoptosis (Fig. $3 F$ ) and could also correspond to one of the slower migrating tau forms seen when calpain is inhibited during apoptosis (Fig. 8A). Inhibition of caspases with VAD-fmk and DEVD-fmk results in a reduction in the $17 \mathrm{kDa}$ Tau- 1 band and the appear- ance of a Tau-1-positive form of tau that is 2-4 kDa smaller than full length, probably the result of a tau cleavage very close to the end, by the action of another protease (calpain) (Fig. 9A). These results can be interpreted in a number of different ways. (1) Tau is cleaved by caspases, and caspase cleavage is required for efficient calpain cleavage; (2) changes in the level of the $17 \mathrm{kDa}$ fragment are a result of the effects of caspase inhibitors on apoptosis itself, although this effect is slight in our system; and (3) caspases are able to control calpain activation either directly or indirectly. The treatment of in vitro translated tau by caspase- 3 
Potential calpain-specific cleavage sites

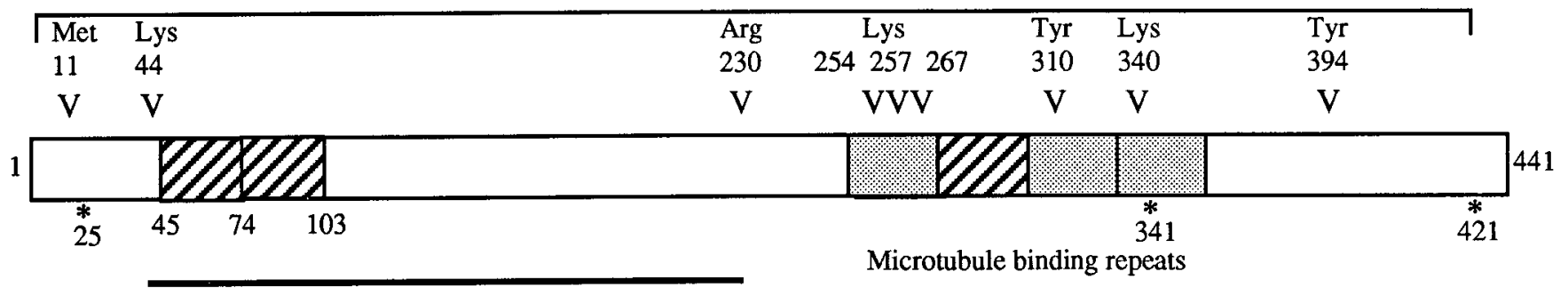

predicted $12.8,15.7$ or $18.6 \mathrm{kDa}$ fragment after calpain

digestion

Figure 10. Map of tau with potential protease sites. The longest form of tau is indicated. V, Potential calpain sites. *, Potential caspase-3 sites. Hatched areas, Alternative spliced exons. Stippled areas, Microtubule binding repeats. Note that cleavage of tau at the $\mathrm{N}$ or $\mathrm{C}$ terminus by calpain or caspase would lead to production of a fragment of tau of similar molecular weight. Note that complete digestion of tau by calpain would lead to the production of 17 $\mathrm{kDa}$ fragment.

(Fig. 9C) clearly reveals that tau can act as an in vitro substrate for this protease, producing fragments of the size expected if the $\mathrm{N}$ and C-terminal sites, but not that at 341, were used. Unfortunately, analysis of tau cleavage by caspases during apoptosis is complicated by the presence of multiple tau isoforms, a complex phosphorylation pattern, and the fact that caspase cleavage occurs very close to the ends of tau and not by release of a diagnostic fragment as occurs with calpain.

Exposure of CGC to potassium and serum deprivation results in a general decrease in phosphorylation (increased tau- 1 and decreased PHF-1, AT8, and 12E8 immunoreactivity) (Fig. 6A). This could be attributable to increases in protein phosphatase or decreases in kinase activity. We have found that [as reported by Gong et al. (1994a)] the epitope recognized by Tau-1 is probably dephosphorylated by phosphatase $2 \mathrm{~A}$ and 1 , because its appearance is inhibited by okadaic acid and calciculin A (data not shown). It is known that phosphatase PP2B/calcineurin is activated by calpain (Saido et al., 1994), and this too, could contribute to tau dephosphorylation (Gong et al., 1994b). Preliminary data from our laboratory in support of this indicate that calcineurin is activated during $\mathrm{K}^{+}$deprivation-induced apoptosis in CGC.

We have been unable to determine whether dephosphorylation precedes or follows tau cleavage. It is reported that dephosphorylation renders tau more vulnerable to proteolysis (Litersky and Johnson, 1992) but also increases the ability to bind to microtubules (Lindwall and Cole, 1984; Drubin and Kirschner, 1986). On the basis of these findings, the effect of tau dephosphorylation would be expected to be an initial, increased microtubule binding (a direct effect of dephosphorylation) followed by a decrease (as a consequence of cleavage secondary to dephosphorylation), which mirrors the findings we describe here (Figs. 3, 4).

Our data for the first time suggest that cleavage of tau, by the concerted action of calpain and caspase, may play an important role in the structural and biochemical changes associated with apoptosis. Beyond its role in modulating microtubules dynamics, tau also interacts with the plasma membrane through its amino terminal region (Brandt et al., 1995). It has been proposed that this interaction increases the affinity of tau for microtubules (Brandt et al., 1995). The cleavage of the tau $\mathrm{N}$ terminus by caspase-3 or calpain or both could therefore reduce the affinity of tau for microtubules, thus leading to a greater fraction of tau susceptible to complete degradation by calpain (appearance of 17 $\mathrm{kDa}$ ). The N-terminal domain also serves as an anchoring device for cellular proteins, notably kinases and phosphatases (Mandelkow et al., 1992; Sontag et al., 1995). Thus it is tempting to speculate that tau cleavage contributes not only to the destabilization of the microtubule network and impairment of signal transduction but also to a loss of the interaction between tau and other cellular proteins. It has also been reported that tau interacts with actin (Correas et al., 1990) and $\alpha$-spectrin (Carlier et al., 1984), the latter being cleaved, both by caspases and calpain, in GCC undergoing apoptosis (Nath et al., 1996). Thus, cleavage of these two proteins could amplify any signal that leads to destabilization, not only of the microtubule network but also of the cortical cytoskeleton. Furthermore, it has been shown (Fasulo et al., 1998) that cleaved tau can itself induce apoptosis. This latter result, coupled with our findings, suggests that tau cleavage could initiate a positive feedback cycle with cell death as the final outcome.

In the brains of patients with $\mathrm{AD}$, the cytoskeleton is gradually damaged and replaced by bundles of PHFs, which are largely composed of abnormally processed forms of tau (Grundke-Iqbal et al., 1986a; Wischik et al., 1988; Brion et al., 1991; Iqbal et al., 1994).

It has been suggested that the underlying pathogenesis of AD may involve inappropriate apoptosis as detected by DNA fragmentation (Su et al., 1994), a finding that has been associated with tau cleavage in AD (Ugolini et al., 1997). Inappropriate imbalances between proteases and protease inhibitors are known to occur in AD (Saido et al., 1994) and are believed to be involved in the pathogenesis of Alzheimer's disease. In light of this, our observations may provide further insight into the pathogenesis of this disease.

\section{REFERENCES}

Biernat J, Gustke N, Drewes G, Mandelkow EM, Mandelkow E (1993) Phosphorylation at Ser 262 strongly reduces binding of tau to microtubules: distinction between PHF-like immunoreactivity and microtubule binding. Neuron 11:153-163.

Bonfoco E, Ceccatelli S, Manzo L, Nicotera L (1995) Colchicine induces apoptosis in cerebellar granule cells. Exp Cell Res 218:189-200.

Brancolini C, Lazarevic D, Rodriguez J, Schneider C (1997) Dismantling cell-cell contacts during apoptosis is coupled to caspasedependent proteolytic cleavage of $\beta$-catenin. J Cell Biol 139:759-771.

Brandt R, Leger J, Lee G (1995) Interaction of tau with the neural plasma membrana by tau's amino-terminal projection domain. J Cell Biol 131:1327-1340.

Brion JP, Hanger DP, Bruce MT, Couck AM, Flament-Durand J, Anderton BH (1991) Tau in Alzheimer neurofibrillary tangles. N- and 
C-terminal regions are differentially associated with paired helical filaments and the location of a putative abnormal phosphorylation site. Biochem J 273:127-133.

Burack MA, Halpain S (1996) Site-specific regulation of Alzheimer-like tau phosphorylation in living neurons. Neuroscience 72:167-184.

Carlier MF, Simon C, Cassoly R, Pradel LA (1984) Interaction between microtubule-associated protein tau and spectrin. Biochimie 66:305-311.

Cohen GM (1997) Caspase: the executioners of apoptosis. Biochem J 326:1-16.

Cohen JJ (1993) Apoptosis. Immunol Today 14:126-130.

Correas I, Padilla R, Avila J (1990) The tubulin-binding sequence of brain microtubule-associated proteins, tau and MAP2, is also involved in actin binding. Biochem J 269:61-64.

Cryns V, Bergeron L, Zhu H, Li H, Yuan J (1996) Specific cleavage of a-fodrin during Fas- and tumor necrosis factor-induced apoptosis is mediated by an interleukin- $1 \beta$-converting enzyme/ced-3 protease distinct from the poly(ADP-ribose) polymerase protease. J Biol Chem 271:31277-31282.

De la Monte SM, Sohn YK, Wands JR (1997) Correlates of p53- and Fas (CD95)-mediated apoptosis in Alzheimer's disease. Neurol Sci 152:73-83.

D'Mello SR, Galli, C, Ciotti MT, Calissano P (1993) Induction of apoptosis in cerebellar granule neurons by low potassium: inhibition of cell death by insulin-growth factor I and cAMP. Proc Natl Acad Sci USA 90:10989-10993.

Drechsel DN, Hyman AA, Cobb MH, Kirschner MW (1992) Modulation of the dynamic instability of tubulin assembly by the microtubuleassociated protein tau. Mol Biol Cell 3:1141-1154.

Drubin DG, Kirschner MW (1986) Tau protein function in living cells. J Cell Biol 103:1583-1591.

Fasulo L, Visintin M, Novak M, Cattaneo A (1998) Tau truncation in Alzheimer's disease: expression of a fragment encompassing PHF core tau induces apoptosis in COS cells. Alzheimer's Rep 1:1-7.

Galli C, Meucci O, Scorziello A, Werge T, Calissano P, Schettini G (1995) Apoptosis in cerebellar granule cells is blocked by high $\mathrm{KCl}$, forskolin, and IGF-1 through distinct mechanism of action: the involvement of intracellular calcium and RNA synthesis. J Neurosci 15:1172-1179.

Gallo V, Giovannini C, Levi G (1980) Modulation of non- $N$-methyl-Daspartate receptors in cultured cerebellar granule cells. J Neurochem 54:1619-1625.

Goedert M, Jakes R (1990) Expression of separate isoforms of human tau protein: correlation with the tau pattern in brain and effects on tubulin polymerization. EMBO J 9:4225-4230.

Goedert M, Spillantini MG, Jakes R, Rutherford D, Crowther RA (1989) Multiple isoforms of human microtubule-associated protein tau: sequences and localization in neurofibrillary tangles of Alzheimer's disease. Neuron 3:519-526.

Goedert M, Crowther RA, Garner CC (1991) Molecular characterization of microtubule-associated proteins tau and MAP2. Trends Neurosci 14:193-199.

Goedert M, Spillantini MG, Cairns NJ, Crowther RA (1992) Tau proteins of Alzheimer paired helical filaments: abnormal phosphorylation of all six brain isoforms. Neuron 8:159-168.

Gong CX, Singh TJ, Grundke-Iqbal I, Iqbal K (1994a) Alzheimer's disease abnormally phosphorylated tau is dephosphorylated by protein phosphatase-2B (calcineurin). J Neurochem 62:803-806.

Gong CX, Grundke-Iqbal I, Iqbal K (1994b) Dephosphorylation of Alzheimer's disease abnormally phosphorylated tau by protein phosphatase-2A. Neuroscience 61:765-772.

Greenberg SG, Davies P, Schein JD, Binder LI (1992) Hydrofluoric acid-treated tau-PHF proteins display the same biochemical properties as normal tau. J Biol Chem 267:564-569.

Grimm LM, Goldberg A, Poirier GG, Schwartz LM, Osborne B (1996) Proteasomes play an essential role in thymocyte apoptosis. EMBO J 15:3835-3844.

Grundke-Iqbal I, Iqbal K, Tung YC, Quinlan M, Wisniewski HM, Binder LI (1986a) Abnormal phosphorylation of the microtubule-associated protein $\tau$ (tau) in Alzheimer cytoskeletal pathology. Proc Natl Acad Sci USA 83:4913-4917.

Grundke-Iqbal I, Iqbal K, Quinlan M, Tung YC, Zaidi MS, Wisniewski HM (1986b) microtubule-associated protein $\tau$ : a component of Alzheimer paired helical filaments. J Biol Chem 261:6084-6089.

Guenette RS, Tenniswood M (1994) The role of growth factors in the suppression of active cell death in the prostate: an hypothesis. Biochem Cell Biol 72:553-559.

Gustke N, Trinczek B, Biernat J, Mandelkow EM, Mandelkow E (1994) Domains of tau protein and interaction with microtubules. Biochemistry 33:9511-9522.

Himmler A, Drechsel D, Kirschner MW, Martin Jr DW (1989) Tau consists of a set of proteins with repeated C-terminal microtubule binding domains and variable N-terminal domains. Mol Cell Biol 9:1381-1388.

Hirokawa N (1994) Microtubule organization and dynamics dependent on microtubule-associated proteins. Curr Opin Cell Biol 6:74-81.

Iqbal K, Zaidi T, Bancher C, Grundke-Iqbal I (1994) Alzheimer paired helical filaments. Restoration of the biological activity by dephosphorylation. FEBS Lett 349:104-108.

Kerr JFR, Wyllie AH, Currie AR (1972) Apoptosis: a basic biological phenomenon with wide-ranging implications in tissue kinetics. $\mathrm{Br} \mathrm{J}$ Cancer 26:239-257.

Kilmartin JV, Wright B, Milstein C (1982) Rat monoclonal antitubulin antibodies derived by using a new nonsecreting rat cell line. J Cell Biol 3:76-82.

Laemmli UK (1970) Cleavage of structural proteins during assembly of the head of bacteriophage T4. Nature 227:682-685.

Ledesma MD, Bonay P, Colaco C, Avila J (1994) Analysis of microtubule-associated protein tau glycation in paired helical filaments. J Biol Chem 269:21614-21619.

Lee VM, Balin B, Otvos Jr L, Trojanowski JQ (1991) A68: a major subunit of paired helical filaments and derivatized forms of normal tau. Science 251:675-679.

Levi G, Aloisi F, Ciotti MT, Gallo V (1984) Autoradiographic localization and depolarization-induced release of acidic amino acids differentiating cerebellar granule cells cultures. Brain Res 290:77-86.

Lindwall G, Cole RD (1984) Phosphorylation affects the ability of tau protein to promote microtubule assembly. J Biol Chem 259:5301-5305.

Litersky JM, Johnson GVW (1992) Phosphorylation by cAMPdependent protein kinase inhibits the degradation of tau by calpain. J Biol Chem 267:1563-1568.

Lovestone S, Reynolds CH (1997) The phosphorylation of tau: a critical stage in neurodevelopment and neurodegenerative processes. Neuroscience 78:309-324.

Lowry OH, Rosebrough NJ, Farr AL, Randall RJ (1951) Protein measurement with Folin phenol reagent. J Biol Chem 193:265-275.

Mandelkow EM, Drewes G, Biernat J, Gustke N, Van Lint J, Vandenheede JR, Mandelkow E (1992) Glycogen synthetase kinase-3 and the Alzheimer-like state of microtubule-associated protein tau. FEBS Lett 314:315-321.

Mawal-Dewan M, Henley J, Van de Voorde A, Trojanowski JQ, Lee VMY (1994) The phosphorylation state of tau in the developing rat brain is regulated by phosphoprotein phosphatases. J Biol Chem 269:30981-30987.

Mercken M, Vandermeeren M, Lubke U, Six J, Boons J, Vandevoorde A (1992) Monoclonal antibodies with selective specificity for Alzheimer tau are directed against phosphatase-sensitive epitopes. Acta Neuropathol 84:265-272.

Nath R, Raser KJ, Stafford D, Hajimohammadreza I, Posner A, Allen H, Talanian R, Yuen P, Gilbertsen RB, Wang KKW (1996) Nonerythroid $\alpha$-spectrin breakdown by calpain and interleukin $1 \beta$ converting-enzyme-like protease(s) in apoptotic cell: contributory roles of both protease families in neuronal apoptosis. Biochem $\mathrm{J}$ 319:683-690.

Neumar RW, Hagle SM, DeGracia DJ, Krause GS, White BC (1996) Brain mCalpain autolysis during global cerebral ischemia. J Neurochem 66:421-424.

Novak M, Jakes R, Edwards PC, Milstein C, Wischik CM (1991) Difference between the tau protein of Alzheimer paired helical filaments core and normal tau revealed by epitope analysis of monoclonal antibodies 423 and 7.51. Proc Natl Acad Sci USA 88:5837-5841.

Novak M, Kabat J, Wischick CM (1993) Molecular characterization of the minimal protease resistant tau unit of the Alzheimer's disease paired helical filament. EMBO J 12:365-370.

Sadoul R, Fernandez PA, Quisquerez AL, Martinou I, Maki M, Schroeter M, Becherer, JD, Irmler M, Tschopp J, Martinou JC (1996) Involvement of the proteasome in the programmed cell death of NGFdeprived sympathetic neurones. EMBO J 15:3845-3852.

Saido TC, Sorimachi H, Suzuki K (1994) Calpain: a new perspective in 
molecular diversity and physiological-pathological involvement. FASEB J 8:814-822.

Saito KI, Elce JS, Hamos JE, Nixon R (1993) Widespread activation of calcium-activated neutral proteinase (calpain) in the brain in Alzheimer disease: a potential molecular basis for neurodegeneration. Proc Natl Acad Sci USA 90:2628-2632.

Sarin A, Clerici M, Blatt SP, Hendrix CW, Shearer GM, Henkart PA (1994) Inhibition of activation-induced programmed cell death and restoration of defective immune response of $\mathrm{HIV}+$ donors by cysteine protease inhibitors. J Immunol 153:862-872.

Seubert P, Mawaldewan M, Barbour R, Jakes R, Goedert M, Johnson GVW, Litersky JM, Schenk D, Lieberburg I, Trojanowski JQ, Lee VMY (1995) Detection of phosphorylated ser (262) in fetal tau, adult tau, and paired helical filament tau. J Biol Chem 270:18917-18922.

Smale G, Nichols NR, Brady DR, Finch CE, Horton WEJ (1995) Evidence for apoptotic cell death in Alzheimer's disease. Exp Neurol 133:225-230.

Sontag E, Numbhakdicraig V, Bloom GS, Mumby MC (1995) A novel pool of protein phosphatase $2 \mathrm{~A}$ is associated with microtubules and is regulated during the cell cycle. J Cell Biol 128:1131-1144.

Soto A M, Sonnenschein C (1985) The role of estrogens on the proliferation of human breast tumor cells (MCF-7). J Steroid Biochem 23:87-94.

Squier MK, Miller AC, Malkinson AM, Cohen JJ (1994) Calpain activation in apoptosis. J Cell Physiol 159:229-237.

Steller H (1995) Mechanism and genes of cellular suicide. Science 267:1445-1449.

Su JH, Anderson AJ, Cummings BJ, Cotman CW (1994) Immunohistochemical evidence for apoptosis in Alzheimer's disease. NeuroReport 5:2529-2533.

Szendrei GL, Lee VMY, Otvos Jr L (1993) Recognition of the minimal epitope of monoclonal antibody Tau-1 depends upon the presence of a phosphate group but not its location. J Neurosci Res 34:243-249.

Thompson C (1995) Apoptosis in the pathogenesis and treatment of disease. Science 267:1456-1462.

Ugolini G, Cattaneo A, Novak M (1997) Co-localisation of truncated tau and DNA fragmentation in Alzheimer's disease neurones. NeuroReport 8:3709-3712.

Villa P, Henzel W, Sensenbrenner M, Henderson C, Pettman B (1998) Calpain inhibitors, but not caspase inhibitors, prevent actin proteolysis and DNA fragmentation during apoptosis. J Cell Sci 111:713-722.

Villalba M, Bockaert J, Journot L (1997) Pituitary adenylate cyclaseactivating polypeptide (PACAP 38 ) protects cerebellar granule neurons from apoptosis by activating the mitogen-activating protein kinase (MAP kinase) pathway. J Neurosci 17:83-90.

Vitolo O, Ciotti MT, Galli C, Borsello T, Calissano P (1998) Adenosine and ADP prevent apoptosis in cultured rat cerebellar granule cells. Brain Res, in press.

Volonte C, Ciotti MT, Battistini L (1994) Development of a method for measuring cell number: application to CNS primary neuronal culture. Cytometry 17:274-276.

Wang JZ, Gong CX, Zaidi T, Grundke-Iqbal I, Iqbal K (1995) Dephosphorylation of Alzheimer paired helical filaments by protein phosphatase-2A and -2B. J Biol Chem 270:4854-4860.

Wang JZ, Grundke-Iqbal I, Iqbal K (1996) Glycosylation of microtubuleassociated protein tau: an abnormal posttranslational modification in Alzheimer's disease. Nat Med 2:871-875.

Wischik CM, Novak M, Thogersen HC, Edwards PC, Runswick MJ, Jakes R, Walker JE, Milstein C, Roth M, Klug A (1988) Isolation of a fragment of tau derived from the core of the paired helical filament of Alzheimer disease. Proc Natl Acad Sci USA 85:4506-4510 . 